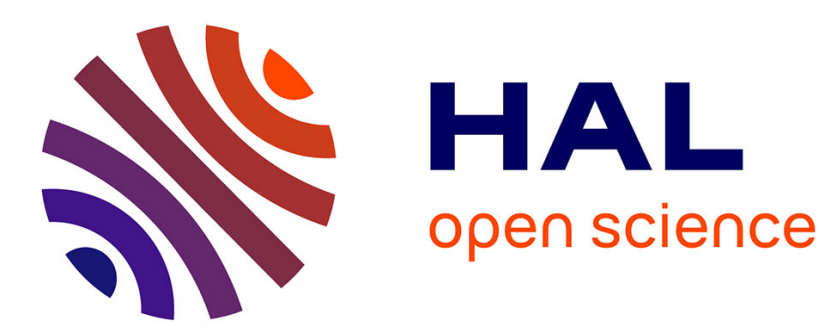

\title{
Biaxial rupture properties of ascending thoracic aortic aneurysms
}

Ambroise Duprey, Olfa Trabelsi, Marco Vola, Jean-Pierre Favre, Stéphane Avril

\section{- To cite this version:}

Ambroise Duprey, Olfa Trabelsi, Marco Vola, Jean-Pierre Favre, Stéphane Avril. Biaxial rupture properties of ascending thoracic aortic aneurysms. Acta Biomaterialia, 2016. hal-01380216

\section{HAL Id: hal-01380216 https://hal.science/hal-01380216}

Submitted on 12 Oct 2016

HAL is a multi-disciplinary open access archive for the deposit and dissemination of scientific research documents, whether they are published or not. The documents may come from teaching and research institutions in France or abroad, or from public or private research centers.
L'archive ouverte pluridisciplinaire HAL, est destinée au dépôt et à la diffusion de documents scientifiques de niveau recherche, publiés ou non, émanant des établissements d'enseignement et de recherche français ou étrangers, des laboratoires publics ou privés. 


\section{Accepted Manuscript}

Biaxial rupture properties of ascending thoracic aortic aneurysms

Ambroise Duprey, Olfa Trabelsi, Marco Vola, Jean-Pierre Favre, Stéphane Avril

PII:

S1742-7061(16)30305-1

DOI: http://dx.doi.org/10.1016/j.actbio.2016.06.028

Reference: ACTBIO 4300

To appear in:

Acta Biomaterialia

Received Date: $\quad 25$ February 2016

Revised Date: $\quad 11$ May 2016

Accepted Date: $\quad 22$ June 2016

Please cite this article as: Duprey, A., Trabelsi, O., Vola, M., Favre, J-P., Avril, S., Biaxial rupture properties of ascending thoracic aortic aneurysms, Acta Biomaterialia (2016), doi: http://dx.doi.org/10.1016/j.actbio. 2016.06.028

This is a PDF file of an unedited manuscript that has been accepted for publication. As a service to our customers we are providing this early version of the manuscript. The manuscript will undergo copyediting, typesetting, and review of the resulting proof before it is published in its final form. Please note that during the production process errors may be discovered which could affect the content, and all legal disclaimers that apply to the journal pertain. 


\section{Biaxial rupture properties of ascending thoracic aortic aneurysms}

$\begin{array}{ll}\text { Ambroise Duprey } & \text { ambroise.duprey@gmail.com } \\ \text { Olfa Trabelsi }^{1,2,3} & \text { olfa.trabelsi1979@gmail.com } \\ \text { Marco Vola }^{4} & \underline{\text { marco.vola@chu-st-etienne.fr }} \\ \text { Jean-Pierre Favre } & \text { j.pierre.favre@chu-st-etienne.fr } \\ \text { Stéphane Avril } & \text { avril@emse.fr }\end{array}$

1. Ecole Nationale Supérieure des Mines de Saint-Etienne, CIS-EMSE, SAINBIOSE, F-42023 Saint Etienne, France

2. INSERM, U1059, F-42000 Saint Etienne, France

3. Université de Lyon, SAINBIOSE, F-42000 Saint Etienne, France

4. University Hospital of Saint-Etienne, Department of Cardiovascular Surgery, F-42055 Saint-

Etienne cedex 2, France

Corresponding author:

Ambroise Duprey

Tel number : 0033477828243

Fax number : 0033477828453

Email : ambroise.duprey@gmail.com

Address : Service de Chirurgie Cardiovasculaire, CHU Saint-Etienne, 42055 cedex 2, FRANCE 


\section{ABSTRACT}

Although hundreds of samples obtained from ascending thoracic aortic aneurysms (ATAA) of patients undergoing elective surgical repair have already been characterized biomechanically, their rupture properties were always derived from uniaxial tensile tests. Due to their bulge shape, ATAAs are stretched biaxially in vivo. In order to understand the biaxial rupture of ATAAs, our group developed a novel methodology based on bulge inflation and full-field optical measurements. The objective of the current paper is threefold. Firstly, we will review the failure properties (maximum stress, maximum stretch) obtained by bulge inflation testing on a cohort of 31 patients and compare them with failure properties obtained by uniaxial tension in a previously published study. Secondly, we will investigate the relationship between the failure properties and the age of patients, showing that patients below 55 years of age display significantly higher strength. Thirdly, we will define a rupture risk based on the extensibility of the tissue and we will show that this rupture risk is strongly correlated with the physiological elastic modulus of the tissue independently of the age, ATAA diameter or the aortic valve phenotype of the patient.

KEYWORDS : aneurysm; human thoracic aorta; bulge inflation test; rupture properties; extensibility. 


\section{INTRODUCTION}

Ascending thoracic aortic aneurysms (ATAA), described at tissue level by medial degeneration and biomechanical weakening of the aneurysmal wall [1,2], are a life-threatening pathology causing a permanent dilation associated with a high risk of aortic rupture or dissection and death of the patient. ATAA affects approximately 10 out of 100000 persons per year [3] and is the $17^{\text {th }}$ most common cause of death [4].

ATAAs are treated by replacing them with synthetic grafts when the aortic diameter exceeds $5.5 \mathrm{~cm}$ [5]. However the rupture or the dissection of ATAAs remains rather unpredictable on a patient-specific basis. Even if the yearly risk of dissection or rupture rises from $3 \%$ to $7 \%$ with aneurysms $>6 \mathrm{~cm}$, rupture of ATAAs has been documented to occur at diameters less than $4.5 \mathrm{~cm}[6]$. Factors other than the aneurysm diameter that may affect the predisposition to rupture are age, hypertension, aortic valve phenotype (bicuspid or tricuspid) or the presence of genetic disorders (Marfan syndrome, Ehler-Danlos syndrome).

Rupture of an ATAA occurs when the stress applied to the aortic wall locally exceeds its capacity to sustain stress. Finite-element analyses can be used to estimate the local distribution of the stress applied by the blood pressure onto the aortic wall [7-9]. An open question is to estimate the patientspecific strength, which can vary from a few tenths of MPa to a few units of MPa from one individual to another $[10,11]$. Another open question is that mean physiological wall stresses acting on pathologic aortas were found to be far from rupture, with factors of safety (defined as the ratio of tensile strength to the mean wall stress) larger than six [12].

Another equivalent definition of rupture can be stated when the stretch applied to the tissue exceeds its extensibility. For instance, Martin et al. [13] defined a diameter risk, which is the ratio between the current diameter of the aneurysm and the rupture diameter. The authors show that the diameter risk increases significantly with the physiological elastic modulus of the artery. Indeed, if the aortic wall is stiff, a rather large increase of pressure can be induced by a small increase of volume. 
In vitro mechanical characterization of ATAA rupture on specimens, obtained from ascending aorta tissue of patients undergoing elective surgical repair, has been instrumental to improve the understanding of the aortic wall properties and the potential risk for rupture of ATAAs [14]. Several authors have focused on elastic properties of ATAAs [9,15-17]. They showed that ATAAs have altered collagen fiber architecture in the medial plane and have significantly less elastin than healthy tissue. The tissue is generally stiffer in the circumferential direction than in the longitudinal direction and the elastic properties vary regionally [16]. Stress-strain analyses also aided in determining material properties [18-20]. Kim and Baek showed significant spatial variations of mechanical properties in a porcine thoracic aorta using optical full-field measurements and inflation-extension tests [21].

Despite the interest of these studies on elastic properties, we will focus on the rupture properties of ATAAs. At least 11 papers reported rupture properties of ascending thoracic aortas and ATAAs in uniaxial tension (Table 1). In these studies, the strength was always determined in uniaxial tension, except for a few samples that were reported in the second paper of Mohan and Melvin where they performed bulge inflation tests [22].

Due to their bulge shape, aneurysm tissues are stretched biaxially in vivo [23], and there is no guarantee that results obtained from a uniaxial test can be applied to a biaxial state. The lack of rupture analysis in biaxial tension can be explained by the fact that biaxial testing is less suitable for strength assessment, due to attachment techniques and the square shape of the specimen, which may prevent failure of the specimen in the gauge area.

Bulge inflation test is another technique for investigation of biaxial mechanical behavior, which has been applied in the past to the study of human and pig aortas $[22,24]$ as well as other soft tissues [25]. The basic testing protocol consists in obtaining square specimens from an excised cylindrical aortic tissue laid flat. These are clamped in the inflation device forming a hermetically sealed cavity in which a fluid (water) is injected at a controllable rate while simultaneously measuring pressure.

Our group recently conducted bulge inflation tests on human ATAA tissues [26-28], to test media/adventitia samples as well as complete layers. Stereo-digital image correlation (SDIC) was 
used to obtain the strain field of the entire inflated membrane. Video-based tracking techniques can allow simultaneous evaluation of material parameters for constitutive modeling purposes and of localized stress in the area that eventually ruptures, providing a powerful experimental tool to characterize the mechanical properties of vascular tissues [17,26,29-32].

The objective of the current paper is threefold. Firstly, we will review the failure properties (maximum stress, maximum stretch) obtained by bulge inflation testing on a cohort of 31 patients undergoing elective surgical repair and compare them with failure properties obtained by uniaxial tension in a previously published study. Secondly, we will investigate the relationship between the failure properties and the age of patients. Thirdly, we will define a rupture risk based on the brittleness of the tissue and investigate the correlation between this rupture risk and the physiological elastic modulus of the tissue.

\section{METHODS}

\subsection{Materials for bulge inflation tests}

ATAA samples for bulge inflation tests were obtained from patients undergoing elective surgery to replace the pathological segment of aorta with a synthetic graft. The collection of the aortic tissues was carried out in accordance with the guidelines of the Institutional Review Board of the University Hospital Center of Saint-Etienne and patients signed informed consent before surgery. Specimens were kept at $+4^{\circ} \mathrm{C}$ in a $0.9 \%$ physiological saline solution and tests were performed within 24 hours [33]. The demographic information for all the aortic specimens used in this study is presented in Table 2.

The aortic samples (Fig. 1a) were cut in the axial direction (in the direction of blood flow) at the level of the inner curvature (Fig. 1b). Then a flat square piece was cut consisting of the tunica intima, media, adventitia and loose connective tissue (Fig. 1c). For all the specimens the loose connective tissue was carefully removed to prevent sliding in the experimental device using dissecting bluntpoint scissors. The thickness of each specimen, denoted $h_{0}$, was measured using a digital caliper 
while holding the specimen between two plates. All the aortic tissues were tested in bulge inflation. The entire process was recorded using a SDIC system to reconstruct the 3D shape of the inflated tissues. The experimental set-up and the bulge inflation tests performed by our group are explained in details in previous publications $[27,28,34]$. The aim of the present study is to review the failure properties (maximum stress, maximum stretch) obtained by the bulge inflation test and compare them with failure properties obtained by uniaxial testing.

\subsection{Materials for uniaxial tensile tests}

We carried out tensile tests on 103 ATAA samples collected from 12 patients at the University of Michigan in 2008. Elastic properties were reported in a previous publication [16] but the rupture properties were not reported. They will be reported herein and compared to the biaxial rupture properties.

All procedures for the uniaxial tensile tests were carried out in accordance with the guidelines of the Institutional Review Board of the University of Michigan and patients signed informed consent. A segment of aortic wall was excised from surgical specimens obtained from patients undergoing elective surgical repair of their ATAA. These segments were cut with custom-designed tissue cutters and multiple test specimens were available when the surgical aortic specimen was large enough. About half of the specimens were cut along the circumferential direction of the aorta and the other half along the axial direction, for the sake of comparison.

Experiments were carried out using a tensile testing machine (Instron model 5542, Norwood, MA, USA). To avoid damaging the tissue from excessive compression, fine grit adhesive sand paper was placed on the surface of the pneumatic grips to prevent slippage during the test. The tissue was kept wet by a spray of phosphate buffering solution. The specimen was stretched at a rate of $10 \mathrm{~mm} \cdot \mathrm{min}^{-1}$ until failure. Load and cross-head displacement were continuously recorded by the data acquisition software Merlin, provided by Instron.

\subsection{Analysis method in bulge inflation tests}


The 3D shape of the inflated ATAA layer captured in vitro, was numerically discretized in order to create a mesh across the 3D shape [27]. Using a finite difference method, the membrane deformation gradient was calculated based on the deformed and initial tangent vectors at each element of the mesh, and the Cauchy-Green stretch tensor was derived from the deformation gradient [27].

Assuming that the tested samples behave as a pure membrane, it is also possible to derive the Cauchy stress at each element of the mesh $[27,34,35]$.

Let $\left(\mathbf{e}_{1}, \mathbf{e}_{2}\right)$ denote the cartesian basis of the circumferential and axial directions of the tissue, respectively. In the current paper, where we analyze experiments for which the rupture occurred in the central region of the specimen, we derived the following data for each sample :

1. $\lambda_{1}$ and $\lambda_{2}$ are the circumferential and axial components of the stretch at the center of the specimen, respectively.

2. $\sigma_{1}$ and $\sigma_{2}$ are the circumferential and axial components of the Cauchy stress tensor at the center of the specimen, respectively.

For each pressure stage $P(t), \lambda_{1}(t), \lambda_{2}(t), \sigma_{1}(t)$ and $\sigma_{2}(t)$ were derived as the average value of the respective stretch or stress fields across a region of $2 \mathrm{~cm}$ radius around the center. It was checked that the in plane shear stresses and strains are negligible in the central region.

In order to determine the stage $t_{\text {physio }}$ corresponding to the average physiological state of the tissue in vivo, we approximated the circumferential stress in the bulging region of the aneurysm with the Laplace law:

$$
\sigma_{1}=\left(P_{\text {in }} D\right) /(4 h)
$$

where $\sigma_{1}$ is an estimate of the average circumferential stress in vivo, $\mathrm{P}_{\text {in }}$ is the average physiological pressure (mean between diastolic and systolic pressure measured by sphygmomanometry for each patient), $\mathrm{D}$ is the diameter of the aneurysm measured from the CT scan, and $\mathrm{h}$ is the current thickness of the wall in vivo, defined as:

$$
h=h_{0} /\left[\lambda_{1}\left(t_{\text {physio }}\right) \lambda_{2}\left(t_{\text {physio }}\right)\right]
$$


The physiological tangent modulus (E) of the specimen is defined as:

$E\left(t_{\text {physio }}\right)=d \sigma_{1}\left(t_{\text {physio }}\right) / d \varepsilon_{1}\left(t_{\text {physio }}\right)(3)$

where $d \varepsilon_{1}$ denotes the infinitesimal circumferential strain that occurs in vivo when the circumferential Cauchy stress varies due to blood pressure variations. The infinitesimal circumferential strain is defined as the ratio between the change of circumference and the average circumference in vivo. An equivalent ratio in the bulge test is $d \varepsilon_{1}=d \lambda_{1} / \lambda_{1}$. Accordingly, we define the physiological tangent modulus as:

$$
E\left(t_{\text {physio }}\right)=\lambda_{1}\left(t_{\text {physio }}\right) d \sigma_{1}\left(t_{\text {physio }}\right) / d \lambda_{1}\left(t_{\text {physio }}\right)
$$

where $d \sigma_{1}\left(t_{\text {physio }}\right) / d \lambda_{1}\left(t_{\text {physio }}\right)$ is the slope of the $\sigma_{1}(t)$ versus $\lambda_{1}(t)$ curve (Figure $\left.3 a\right)$. We consider the elastic modulus along the circumferential direction $\left(\sigma_{1}\right.$ versus $\left.\lambda_{1}\right)$ instead of elastic modulus along the axial direction $\left(\sigma_{2}\right.$ versus $\lambda_{2}$ ) because the changes of blood pressure during the cardiac cycle produce effects which are more significant circumferentially than axially.

For all the bulge inflation tests reported here, the artery burst with a straight crack splitting the media or the entire artery into two halves (Fig 1d and Fig 2). For each test where the crack made a straight line, the vector normal to this line was denoted $\mathbf{e}_{\theta}, \theta$ being the angle between $\mathbf{e}_{\theta}$ and $\mathbf{e}_{2}$ (values reported in Tab. 2). For 8 samples, the crack made an undetermined pattern or covered a large part of the sample and we could not estimate an angle. In these cases, an arbitrary value of $\theta=45^{\circ}$ was assigned.

Using $\boldsymbol{\sigma}$ and $\mathbf{C}$ which are the Cauchy stress tensor and the Right Cauchy Green stretch tensor, respectively, the stress and the stretch components along $\mathbf{e}_{\theta}$ can be derived with the following formulas:

$$
\begin{aligned}
\sigma & =\mathbf{e}_{\theta} \cdot \boldsymbol{\sigma} \cdot \mathbf{e}_{\theta} \\
\lambda^{2} & =\mathbf{e}_{\theta} \cdot \mathbf{C} \cdot \mathbf{e}_{\theta}
\end{aligned}
$$

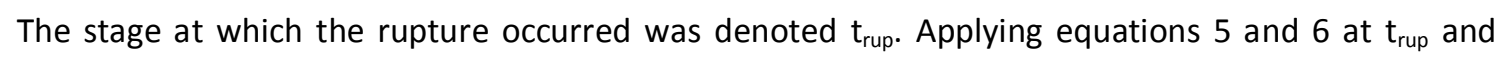
neglecting shear (implying that $\boldsymbol{\sigma}$ and $\mathbf{C}$ are diagonal), it can be written:

$$
\sigma_{\text {rup }}=\sigma_{1}\left(t_{\text {rup }}\right) \cos ^{2} \theta+\sigma_{2}\left(t_{\text {rup }}\right) \sin ^{2} \theta
$$




$$
\lambda_{\text {rup }}=\left\{\left[\lambda_{1}\left(\mathrm{t}_{\text {rup }}\right)\right]^{2} \cos ^{2} \theta+\left[\lambda_{2}\left(\mathrm{t}_{\text {rup }}\right)\right]^{2} \sin ^{2} \theta\right\}^{1 / 2}
$$

Eventually we derived two rupture criteria to evaluate the proximity between the physiological state and the ultimate state where rupture occurred:

1. the first criterion is based on the stress values:

$$
\gamma_{\text {stress }}=\left[\sigma_{1}\left(t_{\text {physio }}\right) / \sigma_{\text {rup }}\right] \cos ^{2} \theta+\left[\sigma_{2}\left(t_{\text {physio }}\right) / \sigma_{\text {rup }}\right] \sin ^{2} \theta
$$

2. the second criterion is based on the stretch values:

$$
\gamma_{\text {stretch }}=\left\{\left[\lambda_{1}\left(t_{\text {physio }}\right) / \lambda_{\text {rup }}\right]^{2} \cos ^{2} \theta+\left[\lambda_{2}\left(t_{\text {physio }}\right) / \lambda_{\text {rup }}\right]^{2} \sin ^{2} \theta\right\}^{1 / 2}
$$

These criteria take values between 0 and 1 . The closer they are to 1 , the larger is the risk of rupture. In structural mechanics, $1 / \gamma$ represents a safety factor.

\subsection{Analysis method in uniaxial tensile tests}

In the uniaxial tensile tests, the tensile Cauchy stress and the tensile stretch were derived from the recorded data $F$ (axial load measured with a load cell) and $L$ (current length of the specimen equal to the initial length $L_{0}$ plus the motion of the cross-head) according to: $\lambda=L / L_{0}, \sigma=F \lambda / S_{0}$, where $\mathrm{S}_{0}$ is the initial cross section area.

$\sigma_{\text {rup }}$ and $\lambda_{\text {rup }}$ were estimated as the stress and stretch values reached at first maximum just before dropping abruptly. This indicated a partial rupture (most of the time in the media) that was followed by tearing of the remaining tissue.

\subsection{Data classification}

We investigated the differences of rupture properties according to 3 different parameters: age, type of test and physiological modulus. Accordingly, patients were classified:

1. in 2 groups of different age: 8 patients $\leq 55$ years old and 23 patients $>55$ years old;

2. in 3 groups of different test type (only for patients $>55)$ : bulge inflation (23 patients), uniaxial tension along the circumferential direction ( 9 patients) and uniaxial tension along the axial direction (8 patients); 
3. in 2 groups of different physiological modulus: 7 patients with $E_{\text {physio }}<1$ and 24 patients with $E_{\text {physio }} \geq 1$.

4. in 2 groups of different type of aortic valve: 8 patients with a bicuspid aortic valve (BAV) and 23 patients with a tricuspid aortic valve (TAV).

\subsection{Statistics}

Relationships among different relevant parameters (age, diameter, $E_{\text {physio, }}, \gamma_{\text {stretch }}, \gamma_{\text {stress }}, \lambda_{\text {rup }}, \sigma_{\text {rup }}$ ) was assessed using Pearson correlation analysis. A normality test was performed using AndersonDarling test for the parametric inference, to determine whether the data in each group of patients followed a normal distribution. One-Way ANOVA with Bonferroni post hoc test was performed to define the statistical differences between groups of patients. The results are presented as mean \pm typical error. The statistical significance was set at $p<0.05$. The statistical methods applied were calculated using Minitab ${ }^{\circledR}$.

\section{RESULTS}

\subsection{Stress-stretch responses in bulge inflation}

A total of 31 different samples were successfully tested with the bulge inflation test. They were collected from the bulging region of ATAAs of 31 patients ranging from 24 to 80 years old. Of interest is the mode of rupture that was observed in these bulge inflation tests. Although some samples burst completely and suddenly at the maximum pressure, in $55 \%$ of them (17 out of 31 ), the intima/media layer failed initially which was characterized by a pressure drop. Afterwards the pressure could be increased again as the adventitia still contained the inflating liquid and resisted rupture. This failure of the intima/media layer occurred with a sudden crack crossing at least half of the sample width. Following this crack, the intima/media layer did not bear any load and recoiled elastically. During this elastic recoil the media slipped over the adventitia, indicating that there had been a partial disruption between the two layers. This mode of failure has many similarities with an aortic 
dissection (failure of the media and delamination between the media and the adventitia). We show a few pictures of ruptured samples in Fig. 2 for the sake of illustrating this typical dissection-like mode of rupture.

The stretch/stress curves of all the tests are shown in Fig 3, with the circumferential direction shown in Fig. 3a and the axial direction shown in Fig. 3b. For 32\% of the samples (10 out of 31), the axial stretch tended to be larger than their circumferential counterparts for equivalent stress. For $29 \%$ of the samples (9 out of 31 ), the tendency was the opposite, whereas for the rest (39\% - 12 out of 31) similar stretch was obtained in both directions.

\subsection{Statistical analysis of rupture properties determined in bulge inflation tests}

For the samples which showed the dissection-like mode of rupture, the maximum stress and stretch were measured when the media ruptured, even if the aorta could still bear load due to its preserved adventitia. It was observed that the ultimate stress values and the ultimate stretch values show no correlation with the aneurysm diameter (respectively $p=0.5$ and $p=0.35$ ). However, a correlation with age was noted (both $p<0.01)$.

We show a graphical representation of the ultimate stress and stretch values as a function of age in Fig 4. The biaxial strength measured from the bulge inflation test shows a significant decrease between 20 and 55 years old. After 55 years of age, the values are dispersed around an average of about 0.9 MPa (Fig. 4a). The statistical analysis determined significant differences for the rupture stress $\left(\sigma_{\text {rup }}\right)$ and stretch $\left(\lambda_{\text {rup }}\right)$, and for the physiological modulus ( $\left.E_{\text {physio }}\right)$ between samples from patients $>55$ years old and samples from patients $\leq 55$ years old $(p<0.05)$ (Fig. 5 and Table A1).

Normal distributions were satisfied in both groups of patients for $\sigma_{\text {rup }}, \lambda_{\text {rup }}$ and $E_{\text {physio. }}$.

We also compared statistically the rupture stress $\left(\sigma_{\text {rup }}\right)$ and stretch $\left(\lambda_{\text {rup }}\right)$ between BAV and TAV patients, but no correlation was found (respectively $p=0.48$ and $p=0.12$ ).

\subsection{Stress-stretch responses in uniaxial tension}


A total of 103 different samples were successfully tested in uniaxial tension. They were collected from ATAAs of 12 patients ranging from 39 to 76 years old. For each patient, the average ultimate stress and stretch in both directions (circumferential and axial) are reported in Table 3. The values of ultimate stress are superimposed with the biaxial results in Fig 4a. It can be observed that there is a significant difference between the circumferential strength and the axial strength, the latter being on average the half of the former $(p<0.01)$. The variation with age appears marginal for the axial strength whereas a net age-related decrease of the circumferential strength is visible $(p=0.53$ and $p<0.05$ respectively). For patients over 55 years old, the biaxial strength is similar to the axial strength and significantly lower than the circumferential strength (Fig. 6a), whereas for younger patients the biaxial strength tends to be similar to the circumferential strength and higher than the axial strength (confirmation of this trend by statistical analysis would require more patients in this group).

We show a graphical representation of the ultimate stretch values as a function of age in Fig. 4b. All the values show a global decrease with age, without reaching significance $(p=0.06$ and $p=0.3$ for circumferential and axial direction respectively).

The data from the three different mechanical tests (bulge and uniaxial in the circumferential and axial direction) were statistically compared for patients aged $>55$ (Fig 6 and Table A2), confirming that:

1- $\sigma_{\text {rup }}$ is significantly different between bulge and uniaxial tests in the circumferential direction, and between both uniaxial tests (circumferential and axial).

2- $\lambda_{\text {rup }}$ is significantly different between bulge and both uniaxial tests.

3.4. Correlation between rupture criteria, age and physiological modulus for the bulge inflation tests

There was a strong correlation between age and the two rupture criteria $\left(\gamma_{\text {stress }}\right.$ and $\left.\gamma_{\text {stretch }}\right)$ as seen in Fig. $7 a(p<0.01)$. The stress based rupture criterion varies from 0.04 to 0.45 , with an average value 
of 0.15 , showing that the stress in vivo could be multiplied, on average, by a factor higher than 6 to reach the rupture stress. The stretch based rupture criterion is much closer to 1 , with an average value of 0.9 . This means that in the aneurysm, on average, an $11 \%$ increase $\left(\gamma_{\text {stretch }}=0.9\right)$ of the circumference/diameter due to blood flow variations increases the risk of rupture. For the weakest aneurysm, this maximum increase reduces to $3 \%\left(\gamma_{\text {stretch }}=0.97\right)$ and for the strongest, to $25 \%$ $\left(\gamma_{\text {stretch }}=0.8\right)$

Interestingly, a strong correlation is observed between $\gamma_{\text {stretch }}$ and $E_{\text {physio }}(p<0.01)$. In Fig $7 b$, it is shown that most of the patients for whom $\gamma_{\text {stretch }}<0.9$ have moduli below $1 \mathrm{MPa}$ whereas patients for whom $\gamma_{\text {stretch }}>0.9$ have moduli ranging from $1 \mathrm{MPa}$ to $7 \mathrm{MPa}$. Accordingly, two groups were defined with respect to their physiological modulus $\left(E_{\text {physio }} \geq 1\right.$ and $\left.E_{\text {physio }}<1\right)$. The statistical analysis revealed that all variables $\left(\sigma_{\text {rup }}, \lambda_{\text {rup }}, \gamma_{\text {stress }}, \gamma_{\text {stretch }}\right.$ and $\left.E_{\text {physio }}\right)$ had a normal distribution for a pre-determined level of significance of $95 \%(p \geq 0.05)$. It also showed a non-significant difference between both groups of samples for $\gamma_{\text {stress, }}$ which means that the $\gamma_{\text {stress }}$ criterion is independent of the physiological modulus (Fig. 8a and Table A3). Conversely $\gamma_{\text {stretch }}$ presented a significant difference between both groups of

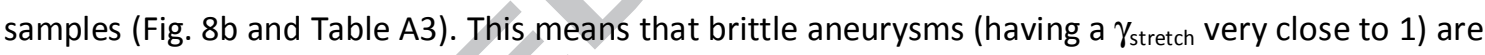
also stiffer. For instance, for an aneurysm having a diameter of $55 \mathrm{~mm}$, a thickness of $2 \mathrm{~mm}$, an elastic modulus of $1 \mathrm{MPa}$, and for a diastolic pressure of $80 \mathrm{mmHg}$ and a systolic pressure of 130 $\mathrm{mmHg}$, we can expect a variation of $9 \%$ of the circumference between diastole and systole by the simple application of the Laplace law.

\section{DISCUSSION}

\subsection{Comparison between uniaxial and biaxial rupture properties of ATAA}

In the present study we have reported for the first time the rupture properties under biaxial loading of 31 human ATAA samples. Due to their bulge shape, ATAA tissue is stretched biaxially in vivo [23]. However, all the rupture properties of ATAAs reported in the literature were characterized 
utilizing uniaxial tension and there was no guarantee that results obtained from a uniaxial test can be applied to a biaxial state.

An interesting aspect of the bulge inflation test is the dissection-like rupture that we observed in most of the samples $[26,27]$, which has never been reported for uniaxial tensile tests but is a common mode of rupture of ATAAs in vivo [4]. Only lliopoulos et al. showed that the inner layer ruptures first in uniaxial tensile tests [36]. Even if the stresses are probably not perfectly equibiaxial in vivo, the bulge inflation test still represents a more relevant mode of loading than the uniaxial tension for characterizing rupture properties of ATAAs.

Uniaxial tensile tests showed that the axial direction of the aortic tissue is always weaker than the circumferential direction $[12,36,37]$. This was observed in most of the published studies which characterized both directions of ATAA samples independently. In the bulge inflation tests, we observed that approximately half of the samples ruptured with a crack perpendicular to the axial direction $\left(\theta=90^{\circ}\right)$. We also observed that the ultimate stress in bulge inflation testing is similar to the axial ultimate stress in uniaxial tension tests for patients $>55$ years old. This confirms that the axial direction is weaker in biaxial loading. A possible explanation for this lower strength in the axial direction is that collagen in the media tend to be aligned in the circumferential direction [38]. This is also consistent with the observed anisotropy in the stress/strain curves, the circumferential direction being generally stiffer. This is a common result with the passive mechanical behavior of the aorta $[18,39,40]$.

Although the circumferential strength is almost double that of the axial direction in uniaxial tests, we observed that the ultimate stretch is similar in both directions, which corroborates other studies [41]. This property of the tissue to reach equivalent ultimate stretch in both direction, despite the anisotropy, brings some complexity to the biaxial behavior which may explain why the rupture does not occur at $\theta^{\sim 90^{\circ}}$ in all the bulge inflation tests.

When stress analyses are performed on ATAAs using finite element analyses [28], different combinations of axial and circumferential stress can be found. In order to determine if rupture may 
occur, failure envelopes taking into account all these different possible combinations are required. Such failure envelopes were previously proposed for abdominal aortic aneurysms [42]. On the one hand, the maximum stretches reported in our study, both in uniaxial tension and equibiaxial tension, are in fairly good agreement with the stretch-based failure envelopes of Volokh [42]. On the other hand, our maximum stresses do not match with the stress-based failure envelopes reported in the Volokh study [42]. The disagreement for the stress may be explained by the assumption of isotropy used to derive the failure envelopes in [42]. Isotropy is not satisfied for ATAA tissue, the strength in the axial direction being half the strength in the circumferential direction. An appropriate failure envelope for ATAAs should be in agreement with both our uniaxial and biaxial data, which requires that it considers anisotropy.

\subsection{Correlation of rupture properties with age and valve phenotype}

Interestingly we also observed that the biaxial strength for patients $\leq 55$ years old tends to be larger than the axial strength, whereas both are similar for patients $>55$ years old. The trends seems to be confirmed for instance by the data of García-Herrera et al. who characterized the rupture properties of 23 subjects between 16 and 57 years old without ATAA and obtained an average axial strength of about 1.2 MPa, which is consistent with our axial strength values at this range of age [12].

These observations lead us to the conclusion that there is an important correlation between the rupture properties of ATAAs and age. This was already established using uniaxial data by Okamoto et al. [10]. In our data, the Pearson test yields a significant correlation between age and both the ultimate stress and ultimate stretch.

Several authors have compared the uniaxial rupture properties of ATAAs between BAV and TAV patients $[12,38,43,44]$. TAV specimens were found significantly weaker than BAV specimens in some studies $[38,43]$ whereas others found no correlation between rupture properties and valve phenotypes $[12,44]$. No correlation was found between the valve phenotype and rupture properties in our biaxial data. 


\subsection{Rupture risk based on the extensibility of the tissue}

The strength of the aortic tissue is generally defined as the maximum stress that the tissue can withstand before failing. However, when we derived the $\gamma_{\text {stress }}$ ratio between the stress applied to the tissue in vivo and its strength, we noted that most of the collected ATAA samples were far from rupture. Another equivalent definition of rupture can be when the stretch applied to the tissue exceeds its extensibility. This way of defining rupture can even be more physiologically meaningful as it is reported that aneurysm rupture or dissections often occur at a time of severe emotional stress or physical exertion [45]. Emotionally or physically stressful situations can induce significant changes of blood volumes in the aorta and more compliant aneurysms are less prone to rupture as they can sustain such changes of volume. Based on this analysis, Martin et al. also defined a similar criterion, named the diameter risk, which is the ratio between the current diameter of the aneurysm and the rupture diameter [13]. They showed that the diameter risk increases significantly with the physiological elastic modulus of the artery. Indeed, if the aortic wall is stiff, a rather large increase of pressure can be induced by a small increase of volume. We showed similar trends in Fig. $7 \mathrm{~b}$ with our biaxial data.

A likely explanation of this phenomenon is the mechanism of collagen recruitment described by Hill et al. [46]. As collagen recruitment increases with the load, the tangent stiffness of the tissue increases too. We can expect that collagen recruitment is delayed in the tissue when it still contains a significant fraction of non-fragmented elastin. At physiological pressures, when elastin is not fragmented, only a small fraction of collagen contributes to the stiffness, which is relatively small (below $1 \mathrm{MPa}$ ). Conversely, when elastic lamella and elastic fibers are highly disrupted, collagen will tend to be recruited earlier and will already contribute significantly to the stiffness at physiological pressures, making the stiffness relatively high (larger than $1 \mathrm{MPa}$ ).

This description of higher recruitment of collagen at physiological pressures corroborates with Iliopoulos et al. [41] who showed that wall elastin, but not collagen content, decreased in ATAA 
specimens, displaying lower wall thickness and failure strain, higher peak elastic modulus, and equal failure stress than control specimens. Moreover, it is commonly observed that the elastin fraction decreases with age, which may explain the trends observed in Fig. 4.

The level of collagen recruitment may explain why $\gamma_{\text {stretch }}$ can be very close to 1 , but not the relatively high values of $\gamma_{\text {stress }}$ that occur for some patients. Indeed, some specimens showed a relatively large extensibility but ruptured at a relatively small stress. When collagen is recruited, it can withstand stresses until damage initiates with ruptures at the fiber level as demonstrated by Weisbecker et al. $[47,48]$. A dense and crosslinked network of collagen will reach larger stresses before the initiation of damage and ultimate stresses.

\subsection{Relationships between rupture properties and tissue histology}

From the above discussion, we submit that two factors play a role in the risk of rupture of ATAAs:

- content and crosslinking of the network of elastic fibers in the media which delays the collagen recruitment and ensures a higher extensibility. The degradation/fragmentation of the elastin network renders ATAAs more brittle $\left(\gamma_{\text {stretch }}>0.9\right)$.

- content and crosslinking of the network of collagen fibers in the media which delays the initiation of damage leading to rupture. The degradation of the collagen network renders ATAAs weaker $\left(\sigma_{\text {rup }}<1 \mathrm{MPa}\right)$

Several authors have highlighted the relationship between the quality of protein networks in the extracellular matrix of ATAAs and the strength and extensibility of the tissue $[43,44,49]$. The degradation of protein networks in the extracellular matrix of ATAAs is explained by the fact that protein production is overwhelmed by protein destruction by the matrix metalloproteases (MMPs), notably MMP-9 which is responsible for elastin degradation. Once the aneurysm process begins, the changes that occur in the thoracic aortic wall lead to increased wall stress, which leads to greater proteolytic activity, which leads to further remodeling, perpetuating a vicious cycle. Once a critical state is reached, the aorta has lost its elastic properties. In the 31 ATAA samples that we tested, the 
state of degradation varied significantly between individuals but it appeared that it was less advanced for patients $\leq 55$ years old. This may mean that protein destruction is slower in young individuals even though they are affected by an ATAA.

\subsection{Limitations and future work}

Due to some current limitations, the following improvements are planned for our future experimental characterizations of ATAA:

1. In this study we used the Laplace law to estimate in vivo physiological conditions (in vivo stress, in vivo tangent modulus) in the bulge region of the aneurysms. Using dynamic gated CT scan and finite-element analyses, this estimation could be refined with a simulation of in vivo physiological conditions as we started to do in preliminary studies [50].

2. The initial or zero-stress thickness was measured using a digital caliper assuming a homogeneous thickness. This should be replaced by a more precise and local measurement where the natural thickness variation of the tissue is taken into account, for example with the use of thickness gauges [51].

3. It would be interesting to distinguish the anterior, posterior and lateral regions of ATAAs as in Iliopoulos et al. and Kim and Baek [21,36], in order to assess possible regional variations of the rupture properties. Here we tested only the outer curvature of the ATAA where the rupture usually occurs.

4. We could apply our approach to healthy ascending aortas as done by Azadani et al. [52], in order to better understand the differences caused in the aortic wall by a pathological state such as aortic insufficiency.

5. Refined histological or immune-histological analyses could be undertaken in order to quantify for instance fiber disruption, mucoid accumulation, loss or hyperplasia of SMCs which are typical of ATAAs.

6. A constitutive model accounting for damage [53-59] could be identified from the stress/strain 
curves.

7. It was assumed that the samples were in a stress-free state at the beginning of each inflation test but residual stresses are actually present in arteries in vivo [60] and it may be interesting to determine how they could affect the ultimate strength and stretch. Similarly the specimens were not perfectly flat at the beginning of the test and this led to some small initial deformation.

\section{CONCLUSIONS}

In this study we characterized the rupture properties of 31 human ATAA samples using bulge inflation testing. To our knowledge this is the first time that in vitro rupture properties of ATAAs are reported and analyzed using biaxial loading conditions. The results have highlighted the relationship between failure properties and the age of patients, showing that patients below 55 years of age display significantly higher strength. We have also shown the correlation between the extensibility of the tissue (which indicates its brittleness) and the physiological elastic modulus, independently of the age, ATAA diameter or the aortic valve phenotype of the patient. The results indicate the combined importance of the quality of the collagen and elastin networks to prevent rupture - elastin quality delaying collagen fiber recruitment and bringing extensibility, and collagen quality delaying fiber damage and bringing strength. Further studies should be done to characterize the underlying mechanobiological mechanisms yielding to the degeneration of these protein networks during the growth of an aneurysm.

\section{CONFLICT OF INTEREST}

None.

\section{ACKNOWLEDGEMENT}

The authors are grateful to the European Research Council for grant ERC-2014-CoG BIOLOCHANICS. The authors would like to thank Prof Ramon Berguer for sharing rupture data and for the inspiring 
discussions.

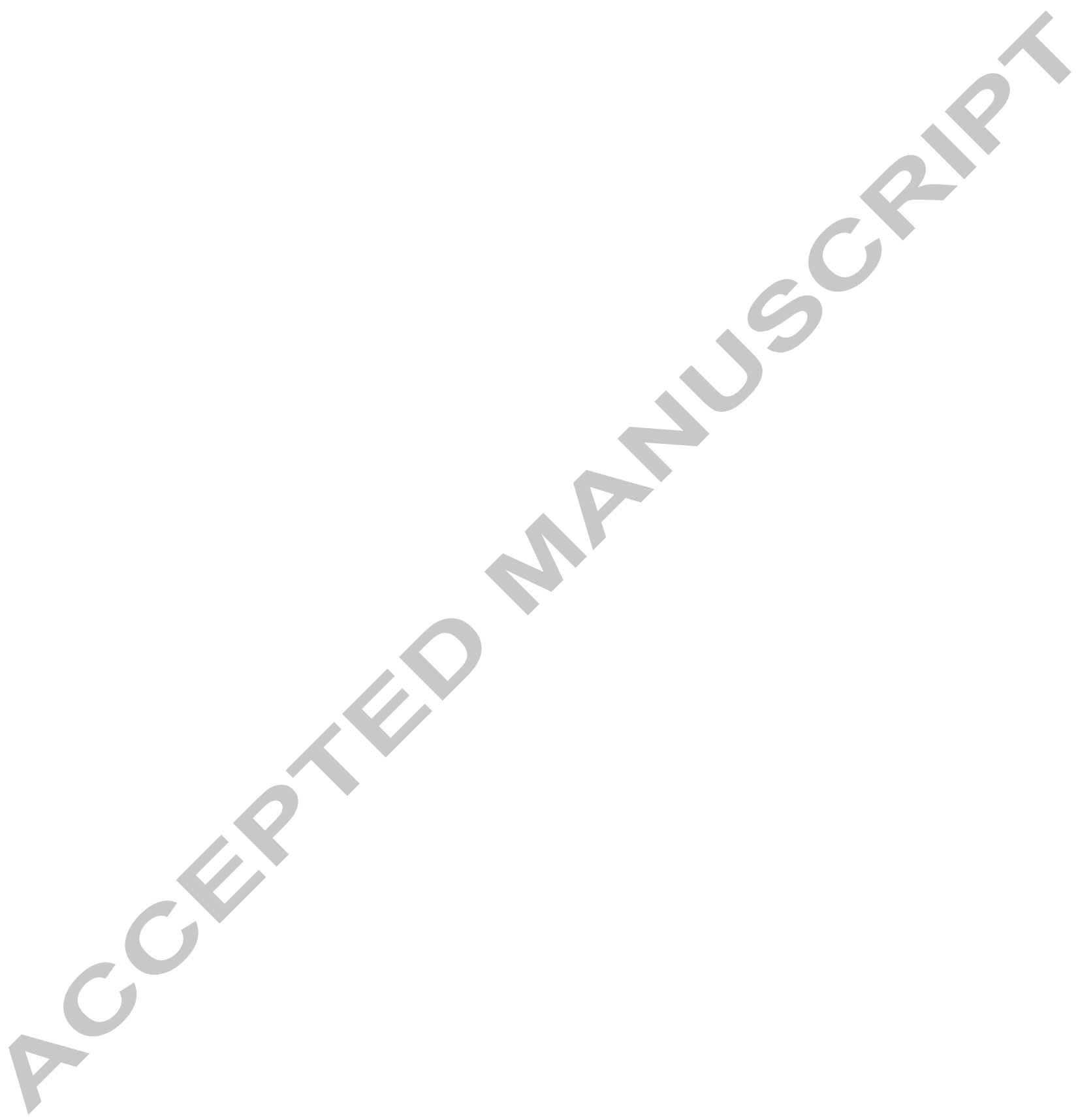




\section{REFERENCES}

[1] J.D. Humphrey, Cardiovascular Solid Mechanics - Cells, Tissues, and Organs, Springer, 2002.

[2] E.M. Isselbacher, Thoracic and Abdominal Aortic Aneurysms, Circulation. 111 (2005) 816-828.

[3] W. Clouse, J.J. Hallett, H. Schaff, M. Gayari, D. Ilstrup, J. Melton III, Improved prognosis of thoracic aortic aneurysms: A population-based study, JAMA. 280 (1998) 1926-1929.

[4] J.A. Elefteriades, Thoracic Aortic Aneurysm: Reading the Enemy's Playbook, Curr. Probl. Cardiol. 33 (2008) 203-277.

[5] J.A. Elefteriades, E.A. Farkas, Thoracic Aortic Aneurysm: Clinically Pertinent Controversies and Uncertainties, J. Am. Coll. Cardiol. 55 (2010) 841-857.

[6] L.A. Pape, T.T. Tsai, E.M. Isselbacher, J.K. Oh, P.T. O’Gara, A. Evangelista, R. Fattori, G. Meinhardt, S. Trimarchi, E. Bossone, T. Suzuki, J.V. Cooper, J.B. Froehlich, C.A. Nienaber, K.A. Eagle, on behalf of the I.R. of A.A.D. (IRAD) Investigators, Aortic Diameter $\geq 5.5 \mathrm{~cm}$ Is Not a Good Predictor of Type A Aortic Dissection Observations From the International Registry of Acute Aortic Dissection (IRAD), Circulation. 116 (2007) 1120-1127.

[7] G. Martufi, T.C. Gasser, J.J. Appoo, E.S.D. Martino, Mechano-biology in the thoracic aortic aneurysm: a review and case study, Biomech. Model. Mechanobiol. 13 (2014) 917-928.

[8] G. Martufi, A. Forneris, J.J. Appoo, E.S. Di Martino, Is There a Role for Biomechanical Engineering in Helping to Elucidate the Risk Profile of the Thoracic Aorta?, Ann. Thorac. Surg. 101 (2016) 390-398.

[9] S. Pasta, J.A. Phillippi, A. Tsamis, A. D’Amore, G.M. Raffa, M. Pilato, C. Scardulla, S.C. Watkins, W.R. Wagner, T.G. Gleason, D.A. Vorp, Constitutive modeling of ascending thoracic aortic aneurysms using microstructural parameters, Med. Eng. Phys. 38 (2016) 121-130.

[10] R.J. Okamoto, J.E. Wagenseil, W.R. DeLong, S.J. Peterson, N.T. Kouchoukos, T.M.S. Iii, Mechanical Properties of Dilated Human Ascending Aorta, Ann. Biomed. Eng. 30 (2002) 624-635.

[11] D.A. Vorp, B.J. Schiro, M.P. Ehrlich, T.S. Juvonen, M.A. Ergin, B.P. Griffith, Effect of aneurysm on the tensile strength and biomechanical behavior of the ascending thoracic aorta, Ann. Thorac. Surg. 75 (2003) 1210-1214.

[12] C.M. García-Herrera, J.M. Atienza, F.J. Rojo, E. Claes, G.V. Guinea, D.J. Celentano, C. García-Montero, R.L. Burgos, Mechanical behaviour and rupture of normal and pathological human ascending aortic wall, Med. Biol. Eng. Comput. 50 (2012) 559-566.

[13] C. Martin, W. Sun, T. Pham, J. Elefteriades, Predictive biomechanical analysis of ascending aortic aneurysm rupture potential, Acta Biomater. 9 (2013) 9392-9400.

[14] A. Avanzini, D. Battini, L. Bagozzi, G. Bisleri, Biomechanical Evaluation of Ascending Aortic Aneurysms, BioMed Res. Int. 2014 (2014).

[15] N. Choudhury, O. Bouchot, L. Rouleau, D. Tremblay, R. Cartier, J. Butany, R. Mongrain, R.L. Leask, Local mechanical and structural properties of healthy and diseased human ascending aorta tissue, Cardiovasc. Pathol. 18 (2009) 83-91.

[16] A. Duprey, K. Khanafer, M. Schlicht, S. Avril, D. Williams, R. Berguer, In Vitro Characterisation of Physiological and Maximum Elastic Modulus of Ascending Thoracic Aortic Aneurysms Using Uniaxial Tensile Testing, Eur. J. Vasc. Endovasc. Surg. 39 (2010) 700-707.

[17] M.R. Labrosse, E.R. Gerson, J.P. Veinot, C.J. Beller, Mechanical characterization of human aortas from pressurization testing and a paradigm shift for circumferential residual stress, J. Mech. Behav. Biomed. Mater. 17 (2013) 44-55.

[18] D. Haskett, G. Johnson, A. Zhou, U. Utzinger, J.V. Geest, Microstructural and biomechanical alterations of the human aorta as a function of age and location, Biomech. Model. Mechanobiol. 9 (2010) 725-736.

[19] E. Maher, A. Creane, C. Lally, D.J. Kelly, An anisotropic inelastic constitutive model to describe stress softening and permanent deformation in arterial tissue, J. Mech. Behav. Biomed. Mater. 12 (2012) 9-19.

[20] E. Maher, M. Early, A. Creane, C. Lally, D.J. Kelly, Site specific inelasticity of arterial tissue, J. Biomech. 45 (2012) 1393-1399.

[21] J. Kim, S. Baek, Circumferential variations of mechanical behavior of the porcine thoracic aorta during the inflation test, J. Biomech. 44 (2011) 1941-1947.

[22] D. Mohan, J.W. Melvin, Failure properties of passive human aortic tissue. II-Biaxial tension tests, J. Biomech. 16 (1983) 31-44.

[23] T. Matsumoto, T. Fukui, T. Tanaka, N. Ikuta, T. Ohashi, K. Kumagai, H. Akimoto, K. Tabayashi, M. Sato, Biaxial Tensile Properties of Thoracic Aortic Aneurysm Tissues, J. Biomech. Sci. Eng. 4 (2009) 518-529.

[24] S.P. Marra, F.E. Kennedy, J.N. Kinkaid, M.F. Fillinger, Elastic and Rupture Properties of Porcine Aortic Tissue Measured Using Inflation Testing, Cardiovasc. Eng. 6 (2006) 123-131.

[25] A. Brunon, K. Bruyère-Garnier, M. Coret, Characterization of the nonlinear behaviour and the failure of human liver capsule through inflation tests, J. Mech. Behav. Biomed. Mater. 4 (2011) 1572-1581. 
[26] J.-H. Kim, S. Avril, A. Duprey, J.-P. Favre, Experimental characterization of rupture in human aortic aneurysms using a full-field measurement technique, Biomech. Model. Mechanobiol. 11 (2011) 841-853.

[27] A. Romo, P. Badel, A. Duprey, J.-P. Favre, S. Avril, In vitro analysis of localized aneurysm rupture, J. Biomech. 47 (2014) 607-616.

[28] O. Trabelsi, F.M. Davis, J.F. Rodriguez-Matas, A. Duprey, S. Avril, Patient specific stress and rupture analysis of ascending thoracic aneurysms, J. Biomech. 48 (2015) 1836-1843.

[29] S. Avril, P. Badel, A. Duprey, Anisotropic and hyperelastic identification of in vitro human arteries from full-field optical measurements, J. Biomech. 43 (2010) 2978-2985.

[30] K. Genovese, Y.U. Lee, J.D. Humphrey, Novel optical system for in vitro quantification of full surface strain fields in small arteries: I. Theory and design, Comput. Methods Biomech. Biomed. Engin. 14 (2011) 213-225.

[31] K. Genovese, Y.U. Lee, J.D. Humphrey, Novel optical system for in vitro quantification of full surface strain fields in small arteries: II. Correction for refraction and illustrative results, Comput. Methods Biomech. Biomed. Engin. 14 (2011) 227-237.

[32] P. Badel, S. Avril, S. Lessner, M. Sutton, Mechanical identification of layer-specific properties of mouse carotid arteries using 3D-DIC and a hyperelastic anisotropic constitutive model, Comput. Methods Biomech. Biomed. Engin. 15 (2012) 37-48.

[33] M. Adham, J.-P. Gournier, J.-P. Favre, E. De La Roche, C. Ducerf, J. Baulieux, X. Barral, M. Pouyet, Mechanical Characteristics of Fresh and Frozen Human Descending Thoracic Aorta, J. Surg. Res. 64 (1996) 32-34.

[34] F.M. Davis, Y. Luo, S. Avril, A. Duprey, J. Lu, Pointwise characterization of the elastic properties of planar soft tissues: application to ascending thoracic aneurysms, Biomech. Model. Mechanobiol. 14 (2015) 967-978.

[35] J. Lu, X. Zhou, M.L. Raghavan, Inverse elastostatic stress analysis in pre-deformed biological structures: Demonstration using abdominal aortic aneurysms, J. Biomech. 40 (2007) 693-696.

[36] D.C. Iliopoulos, R.P. Deveja, E.P. Kritharis, D. Perrea, G.D. Sionis, K. Toutouzas, C. Stefanadis, D.P. Sokolis, Regional and directional variations in the mechanical properties of ascending thoracic aortic aneurysms, Med. Eng. Phys. 31 (2009) 1-9.

[37] D.P. Sokolis, E.P. Kritharis, D.C. Iliopoulos, Effect of layer heterogeneity on the biomechanical properties of ascending thoracic aortic aneurysms, Med. Biol. Eng. Comput. 50 (2012) 1227-1237.

[38] C. Forsell, H.M. Björck, P. Eriksson, A. Franco-Cereceda, T.C. Gasser, Biomechanical Properties of the Thoracic Aneurysmal Wall: Differences Between Bicuspid Aortic Valve and Tricuspid Aortic Valve Patients, Ann. Thorac. Surg. 98 (2014) 65-71.

[39] A. García, E. Peña, A. Laborda, F. Lostalé, M.A. De Gregorio, M. Doblaré, M.A. Martínez, Experimental study and constitutive modelling of the passive mechanical properties of the porcine carotid artery and its relation to histological analysis: Implications in animal cardiovascular device trials, Med. Eng. Phys. 33 (2011) 665-676.

[40] G.A. Holzapfel, T.C. Gasser, R.W. Ogden, A New Constitutive Framework for Arterial Wall Mechanics and a Comparative Study of Material Models, J. Elast. Phys. Sci. Solids. 61 (2000) 1-48.

[41] D.C. Iliopoulos, E.P. Kritharis, A.T. Giagini, S.A. Papadodima, D.P. Sokolis, Ascending thoracic aortic aneurysms are associated with compositional remodeling and vessel stiffening but not weakening in agematched subjects, J. Thorac. Cardiovasc. Surg. 137 (2009) 101-109.

[42] K.Y. Volokh, Comparison of biomechanical failure criteria for abdominal aortic aneurysm, J. Biomech. 43 (2010) 2032-2034.

[43] J.E. Pichamuthu, J.A. Phillippi, D.A. Cleary, D.W. Chew, J. Hempel, D.A. Vorp, T.G. Gleason, Differential Tensile Strength and Collagen Composition in Ascending Aortic Aneurysms by Aortic Valve Phenotype, Ann. Thorac. Surg. 96 (2013) 2147-2154.

[44] T. Pham, C. Martin, J. Elefteriades, W. Sun, Biomechanical characterization of ascending aortic aneurysm with concomitant bicuspid aortic valve and bovine aortic arch, Acta Biomater. 9 (2013) 7927-7936.

[45] C. de Virgilio, R.J. Nelson, J. Milliken, R. Snyder, F. Chiang, W.D. MacDonald, J.M. Robertson, Ascending aortic dissection in weight lifters with cystic medial degeneration, Ann. Thorac. Surg. 49 (1990) 638-642.

[46] M.R. Hill, X. Duan, G.A. Gibson, S. Watkins, A.M. Robertson, A theoretical and non-destructive experimental approach for direct inclusion of measured collagen orientation and recruitment into mechanical models of the artery wall, J. Biomech. 45 (2012) 762-771.

[47] H. Weisbecker, C. Viertler, D.M. Pierce, G.A. Holzapfel, The role of elastin and collagen in the softening behavior of the human thoracic aortic media, J. Biomech. 46 (2013) 1859-1865.

[48] H. Weisbecker, D.M. Pierce, P. Regitnig, G.A. Holzapfel, Layer-specific damage experiments and modeling of human thoracic and abdominal aortas with non-atherosclerotic intimal thickening, J. Mech. Behav. Biomed. Mater. 12 (2012) 93-106. 
[49] A. Tsamis, J.T. Krawiec, D.A. Vorp, Elastin and collagen fibre microstructure of the human aorta in ageing and disease: a review, J. R. Soc. Interface. 10 (2013) 20121004.

[50] O. Trabelsi, A. Duprey, J.-P. Favre, S. Avril, Predictive Models with Patient Specific Material Properties for the Biomechanical Behavior of Ascending Thoracic Aneurysms, Ann. Biomed. Eng. 44 (2015) 84-98.

[51] S.A. O'Leary, B.J. Doyle, T.M. McGloughlin, Comparison of methods used to measure the thickness of soft tissues and their influence on the evaluation of tensile stress, J. Biomech. 46 (2013) 1955-1960.

[52] A.N. Azadani, S. Chitsaz, A. Mannion, A. Mookhoek, A. Wisneski, J.M. Guccione, M.D. Hope, L. Ge, E.E. Tseng, Biomechanical Properties of Human Ascending Thoracic Aortic Aneurysms, Ann. Thorac. Surg. 96 (2013) 50-58.

[53] V. Alastrué, J.F. Rodríguez, B. Calvo, M. Doblaré, Structural damage models for fibrous biological soft tissues, Int. J. Solids Struct. 44 (2007) 5894-5911.

[54] D. Balzani, S. Brinkhues, G.A. Holzapfel, Constitutive framework for the modeling of damage in collagenous soft tissues with application to arterial walls, Comput. Methods Appl. Mech. Eng. 213-216 (2012) 139-151.

[55] D. Balzani, J. Schröder, D. Gross, Simulation of discontinuous damage incorporating residual stresses in circumferentially overstretched atherosclerotic arteries, Acta Biomater. 2 (2006) 609-618.

[56] T.C. Gasser, P. Gudmundson, G. Dohr, Failure mechanisms of ventricular tissue due to deep penetration, J. Biomech. 42 (2009) 626-633.

[57] J.C. Simo, On a Fully Three-Dimensional Finite-Strain Viscoelastic Damage Model: Formulation and, in: Comput. Asp. Comput. Methods Appl. Mech. Eng. 60, 1987: pp. 153-173.

[58] K.Y. Volokh, Prediction of arterial failure based on a microstructural bi-layer fiber-matrix model with softening, J. Biomech. 41 (2008) 447-453.

[59] K.Y. Volokh, Modeling failure of soft anisotropic materials with application to arteries, J. Mech. Behav. Biomed. Mater. 4 (2011) 1582-1594.

[60] Fung, Y.C., Mechanical Properties and Active Remodeling of Blood Vessels, in: Biomech. Mech. Prop. Living Tissues, Springer, 1993: pp. 321-391. 
Table 1. Published studies reporting uniaxial rupture properties of ascending thoracic aortas and ATAAs.

\begin{tabular}{|c|c|c|}
\hline Reference & Tests & Main conclusions \\
\hline $\begin{array}{l}\text { Mohan and } \\
\text { Melvin (1982) }\end{array}$ & 34 aortas in uniaxial tension & $\begin{array}{l}\text { Failure properties of human aortic tissue at quasi- } \\
\text { static and dynamic strain rates }\end{array}$ \\
\hline $\begin{array}{l}\text { Okamoto et al } \\
\text { (2002) }\end{array}$ & $\begin{array}{l}25 \text { ATAAs tested up to failure in } \\
\text { uniaxial tension }\end{array}$ & $\begin{array}{l}\text { Age clearly influences the measured elastic and } \\
\text { strength properties in ATAA }\end{array}$ \\
\hline $\begin{array}{l}\text { Vorp et al. } \\
\text { (2003) }\end{array}$ & $\begin{array}{l}36 \text { ATAAs and } 10 \text { non } \\
\text { aneurysmal ascending thoracic } \\
\text { aortas }\end{array}$ & $\begin{array}{l}\text { ATAA samples are stiffer and approximately } 30 \% \\
\text { weaker than healthy samples }\end{array}$ \\
\hline $\begin{array}{l}\text { Sokolis et al. } \\
\text { (2012) }\end{array}$ & $\begin{array}{l}\text { Uniaxial tensile tests on intima, } \\
\text { media and adventitia }\end{array}$ & $\begin{array}{l}\text { Similar extensibility for all the layers but larger } \\
\text { strength for the adventitia }\end{array}$ \\
\hline $\begin{array}{l}\text { Iliopoulos et } \\
\text { al. (2009a) }\end{array}$ & $\begin{array}{l}\text { Tensile tests on ATAAs sample } \\
\text { of } 12 \text { patients }\end{array}$ & $\begin{array}{l}\text { Inverse correlations of failure stress with thickness } \\
\text { and direct correlations with peak elastic modulus }\end{array}$ \\
\hline $\begin{array}{l}\text { Iliopoulos et } \\
\text { al. (2009b) }\end{array}$ & $\begin{array}{l}\text { Uniaxial tensile tests on } 26 \\
\text { ATAAs and } 15 \text { non aneurysmal } \\
\text { ascending thoracic aortas }\end{array}$ & $\begin{array}{l}\text { ATAA display smaller failure strain, smaller elastin } \\
\text { content and higher peak elastic modulus. } \\
\text { Circumferential specimens show higher failure stress } \\
\text { and peak elastic modulus but equal failure strain }\end{array}$ \\
\hline $\begin{array}{l}\text { Forsell et al. } \\
\text { (2014) }\end{array}$ & $\begin{array}{l}\text { Uniaxial tensile tests on } 24 \\
\text { ATAAs, } 14 \text { patients with } \\
\text { bicuspid aortic valve (BAV) and } \\
10 \text { with tricuspid aortic valve } \\
\text { (TAV) }\end{array}$ & $\begin{array}{l}\text { The strength was almost two times higher in BAV } \\
\text { samples. Collagen related stiffness was significantly } \\
\text { increased in BAV samples whereas elastin related } \\
\text { stiffness was similar in both groups }\end{array}$ \\
\hline $\begin{array}{l}\text { Pichamuthu et } \\
\text { al. (2013) }\end{array}$ & $\begin{array}{l}\text { Uniaxial tensile tests on } 38 \\
\text { ATAAs, } 23 \text { from BAV patients } \\
\text { and } 15 \text { from TAV patients }\end{array}$ & $\begin{array}{l}\text { Circumferential and longitudinal tensile strengths } \\
\text { were higher for BAV ATAAs than TAV ATAAs. } \\
\text { Uniform collagen content between groups }\end{array}$ \\
\hline $\begin{array}{l}\text { Garc } \\
\text { et al }\end{array}$ & $\begin{array}{l}\text { Uniaxial tensile tests on } 26 \\
\text { ATAAs ( } 12 \text { BAV and } 14 \text { TAV) } \\
\text { and } 23 \text { non aneurysmal } \\
\text { ascending thoracic aortas }\end{array}$ & $\begin{array}{l}\text { Age causes a major reduction in the mechanical } \\
\text { parameters of healthy ascending aortic tissue, no } \\
\text { significant differences between the mechanical } \\
\text { strength of aneurysmal TAV or BAV aortic specimens } \\
\text { and the corresponding age-matched control group }\end{array}$ \\
\hline $\begin{array}{l}\text { Pham et al. } \\
\text { (2013) }\end{array}$ & $\begin{array}{l}\text { Uniaxial tensile tests on } 35 \\
\text { ATAAs (20 BAV and } 15 \text { TAV) } \\
\text { and } 20 \text { non aneurysmal } \\
\text { ascending thoracic aortas }\end{array}$ & $\begin{array}{l}\text { No difference of failure properties between the } \\
\text { groups. Moderate medial degeneration } \\
\text { characterized by elastin fragmentation, cell loss, } \\
\text { mucoid accumulation and fibrosis. The ultimate } \\
\text { tensile strength decreases with age }\end{array}$ \\
\hline $\begin{array}{l}\text { Sokolis and } \\
\text { Iliopoulos } \\
\text { (2014) }\end{array}$ & $\begin{array}{l}\text { Uniaxial tensile tests on } 35 \\
\text { ATAAs }(20 / 15 \text { male/female } \\
\text { ratio) }\end{array}$ & $\begin{array}{l}\text { Male ATAAs are stronger but equally extensible in } \\
\text { the circumferential axis compared to female ones. } \\
\text { Longitudinally, instead, gender differences at each } \\
\text { region are insignificant }\end{array}$ \\
\hline
\end{tabular}


Table 2. Demographic information and results of the bulge inflation tests.

\begin{tabular}{|c|c|c|c|c|c|c|c|c|c|}
\hline Id & $\begin{array}{c}\text { Sex/ } \\
\text { Age/Valve }\end{array}$ & $\begin{array}{c}\text { Thickness } \\
(\mathrm{mm})\end{array}$ & $\begin{array}{c}\text { Diameter } \\
(\mathrm{mm})\end{array}$ & $\begin{array}{l}E_{\text {physio }} \\
\text { (MPa) }\end{array}$ & $\begin{array}{c}\sigma_{\text {rup }} \\
(\mathrm{MPa})\end{array}$ & $\lambda_{\text {rup }}$ & $\gamma_{\text {stress }}$ & $\gamma_{\text {stretch }}$ & $\theta\left({ }^{\circ}\right)^{+}$ \\
\hline 1 & F/76/TAV & 1.82 & 55 & 3.69 & 1.31 & 1.19 & 0.09 & 0.94 & 80 \\
\hline 2 & M/64/TAV & 1.99 & 55 & 1.01 & 1.28 & 1.40 & 0.10 & 0.86 & $x$ \\
\hline 3 & M/55/BAV & 2.10 & 65 & 0.96 & 0.79 & 1.48 & 0.22 & 0.88 & 80 \\
\hline 4 & M/76/TAV & 1.98 & 51 & 1.69 & 1.12 & 1.34 & 0.11 & 0.92 & $x$ \\
\hline 5 & M/68/TAV & 1.79 & 55 & 2.05 & 1.17 & 1.51 & 0.16 & 0.94 & $x$ \\
\hline 6 & M/58/BAV & 2.74 & 52 & 0.61 & 1.11 & 1.53 & 0.10 & 0.88 & $x$ \\
\hline 7 & $\mathrm{M} / 66 / \mathrm{TAV}$ & 1.86 & 50 & 0.72 & 0.50 & 1.48 & 0.28 & 0.84 & 90 \\
\hline 8 & $\mathrm{M} / 75 / \mathrm{BAV}$ & 1.70 & 55 & 2.22 & 1.07 & 1.33 & 0.14 & 0.92 & 80 \\
\hline 9 & M/68/BAV & 2.50 & 51 & 2.59 & 0.90 & 1.34 & 0.12 & 0.95 & 90 \\
\hline 10 & M/78/TAV & 2.72 & 50 & 0.62 & 0.65 & 1.39 & 0.13 & 0.84 & 90 \\
\hline 11 & M/68/TAV & 2.20 & 50 & 0.78 & 0.78 & 1.56 & 0.20 & 0.91 & 100 \\
\hline 12 & M/70/TAV & 1.79 & 55 & 2.85 & 1.24 & 1.32 & 0.12 & 0.94 & $\mathrm{x}$ \\
\hline 13 & $\mathrm{M} / 24 / \mathrm{BAV}$ & 1.77 & 50 & 0.61 & 4.84 & 1.70 & 0.04 & 0.81 & 75 \\
\hline 14 & M/64/TAV & 1.79 & 55 & 1.31 & 1.29 & 1.64 & 0.17 & 0.92 & 90 \\
\hline 15 & M/66/TAV & 1.94 & 55 & 1.85 & 0.45 & 1.28 & 0.27 & 0.92 & 80 \\
\hline $16^{*}$ & $\mathrm{M} / 36 / \mathrm{TAV}$ & 0.51 & 50 & 0.69 & 3.60 & 1.52 & 0.04 & 0.83 & 0 \\
\hline $17^{*}$ & M/55/TAV & 1.09 & 53 & 2.20 & 0.82 & 1.33 & 0.18 & 0.95 & 0 \\
\hline $18^{*}$ & $\mathrm{M} / 49 / \mathrm{BAV}$ & 0.95 & 52 & 1.48 & 1.51 & 1.45 & 0.10 & 0.88 & 0 \\
\hline 19 & M/64/TAV & 1.65 & 52 & 2.58 & 0.86 & 1.40 & 0.21 & 0.94 & $x$ \\
\hline 20 & M/79/TAV & 1.79 & 50 & 4.51 & 0.86 & 1.22 & 0.14 & 0.96 & 100 \\
\hline 21 & F/65/TAV & 1.82 & 49 & 5.37 & 0.85 & 1.18 & 0.13 & 0.96 & 100 \\
\hline 22 & F/80/TAV & 1.68 & 52 & 5.34 & 0.40 & 1.12 & 0.30 & 0.98 & 100 \\
\hline 23 & F/80/TAV & 1.68 & 52 & 3.77 & 0.77 & 1.25 & 0.20 & 0.96 & 30 \\
\hline 24 & $\mathrm{M} / 40 / \mathrm{TAV}$ & 1.59 & 55 & 1.20 & 2.30 & 1.55 & 0.09 & 0.88 & $x$ \\
\hline 25 & M/79/TAV & 1.76 & 52 & 4.41 & 0.95 & 1.21 & 0.15 & 0.96 & 0 \\
\hline 26 & M/76/BAV & 1.82 & 58 & 3.28 & 0.33 & 1.25 & 0.51 & 0.98 & 100 \\
\hline 27 & M/72/TAV & 1.90 & 51 & 2.37 & 0.76 & 1.18 & 0.16 & 0.97 & 100 \\
\hline 28 & F/76/TAV & 2.41 & 65 & 2.53 & 1.31 & 1.28 & 0.10 & 0.95 & 70 \\
\hline 29 & M/79/TAV & 1.89 & 54 & 6.52 & 1.67 & 1.20 & 0.07 & 0.94 & 80 \\
\hline 30 & M/55/BAV & 2.35 & 55 & 1.00 & 0.98 & 1.52 & 0.16 & 0.89 & 100 \\
\hline 31 & M/54/TAV & 2.11 & 55 & 1.36 & 2.60 & 1.45 & 0.05 & 0.87 & $x$ \\
\hline Mean & 65 (age) & 1.97 & 53.52 & 2.33 & 1.26 & 1.37 & 0.16 & 0.92 & \\
\hline STD & 13.8 (age) & 0.31 & 3.80 & 1.60 & 0.94 & 0.15 & 0.09 & 0.05 & \\
\hline
\end{tabular}

* for 3 patients, the media and the adventitia were separated as explained in (Romo et al, 2014). The thickness value reported in the table is the thickness of the layer tested in the bulge inflation experiment and it is not taken into account to derive the average and standard deviation of the thickness of the whole population.

${ }^{\dagger}$ an angle $\theta$ of $\mathrm{x}$ means that the crack pattern was undetermined and that it was not possible to estimate an angle. 
Table 3. Demographic information and results of the uniaxial tensile tests.

\begin{tabular}{|c|c|c|c|c|c|c|c|}
\hline Id & $\begin{array}{c}\text { Sex/ } \\
\text { Age/Valve }\end{array}$ & $\begin{array}{c}\text { Thickness } \\
(\mathrm{mm})\end{array}$ & $\begin{array}{c}\text { Diameter } \\
(\mathrm{mm})\end{array}$ & $\begin{array}{c}\text { Circ } \sigma_{\text {rup }} \\
(\mathrm{MPa})\end{array}$ & $\begin{array}{c}\text { Axial } \sigma_{\text {rup }} \\
(\mathrm{MPa})\end{array}$ & $\begin{array}{l}\text { Circ } \\
\lambda_{\text {rup }}\end{array}$ & $\begin{array}{c}\text { Axial } \\
\lambda_{\text {rup }}\end{array}$ \\
\hline 1 & M/69/TAV & 1.73 & 43 & 1.34 & - & 1.50 & - \\
\hline 2 & F/72/BAV & 1.48 & 53 & 1.17 & - & 1.36 & - \\
\hline 3 & M/61/TAV & 2.02 & 51 & 1.54 & 0.51 & 1.77 & 1.33 \\
\hline 4 & M/57/BAV & 2.31 & 55 & 1.31 & 0.45 & 1.69 & 1.44 \\
\hline 5 & M/39/BAV & 1.80 & 52 & 2.81 & 0.76 & 1.95 & 1.91 \\
\hline 6 & M/47/BAV & 1.70 & 50 & - & 0.80 & - & 1.61 \\
\hline 7 & M/75/TAV & 1.65 & 48 & 2.07 & 0.64 & 1.77 & 1.71 \\
\hline 8 & M/76/TAV & 1.52 & 46 & 0.67 & 0.39 & 1.48 & 1.50 \\
\hline 9 & M/75/TAV & 2.01 & 53 & 1.00 & 0.82 & 1.60 & 1.54 \\
\hline 10 & M/68/TAV & 2.02 & 67 & 2.19 & 1.03 & 2.00 & 1.64 \\
\hline 11 & M/61/TAV & 1.50 & 45 & 1.30 & 0.80 & 1.70 & 1.89 \\
\hline 12 & M/55/TAV & 1.79 & 50 & 1.87 & 1.65 & 1.81 & 1.71 \\
\hline Mean & 63 (age) & 1.79 & 51.08 & 1.57 & 0.79 & 1.69 & 1.63 \\
\hline STD & 11.8 (age) & 0.25 & 6.16 & 0.61 & 0.36 & 0.20 & 0.19 \\
\hline
\end{tabular}




\section{Legends of figures}

Figure 1. (a) Picture of an ATAA sample just after collection during aneurysm surgical repair; (b) Picture of an ATAA sample after cutting the inner curvature and opening; (c) Picture of an ATAA sample after cutting the square sample that will be tested in the bulge inflation bench; (d) Picture of an ATAA sample after rupture in the bulge inflation test.

Figure 2. Pictures taken by the digital camera of the DIC system after rupture of ATAA samples in the bulge inflation test. (a) patient 10; (b) patient 13; (c) patient 14; (d) patient 11. Pictures are taken from above the sample. More details about the experimental arrangements may be found in [27].

Figure 3. Stress/stretch curves obtained on the 31 samples tested with the bulge inflation test. (a) Circumferential Cauchy stress versus circumferential stretch; (b) Axial Cauchy stress versus axial stretch.

Figure 4. (a) Age related variations of the ultimate strength $\sigma_{\text {rup }}$ in uniaxial tensile tests and in bulge inflation tests $(p<0.01)$; (b) Age related variations of the ultimate stretch $\lambda_{\text {rup }}$ in uniaxial tensile tests and in bulge inflation tests $(p<0.01)$

Figure 5. Significant differences between both populations (age $\leq 55$ and age $>55$ ) of (a) $\sigma_{\text {rup }}$ (b) $\lambda_{\text {rup }}$ and (c) Ephysio.

Figure 6. Statistical comparison between the 3 different types of tests (bulge inflation, uniaxial tension along the circumferential and uniaxial direction) of the distributions of (a) $\sigma_{\text {rup }}$ and (b) $\lambda_{\text {rup }}$.

Figure 7. (a) Age related variations of both rupture criteria $\gamma_{\text {stress }}$ and $\gamma_{\text {stretch }}$ determined from bulge inflation tests $(p<0.01)$; (b) Variations of $\gamma_{\text {stretch }}$ with respect to the physiological elastic modulus $(p<0.01)$.

Figure 8. Statistical comparison between both populations $\left(E_{\text {physio }}<1\right.$ and $E_{\text {physio }} \geq 1$ ) of the distributions of (a) $\gamma_{\text {stress }}$ and (b) $\gamma_{\text {stretch. }}$. 


\section{Appendix}

Table A1. Statistical distributions (mean and typical error) for both populations (age $\leq 55$ and age > 55) for $\sigma_{\text {rup }}, \lambda_{\text {rup }}$ and $E_{\text {physio }}$

\begin{tabular}{|c|c|c|c|c|c|c|}
\hline \multirow{2}{*}{ Bulge test } & \multicolumn{2}{|c|}{$\sigma_{\text {rup }}(\mathrm{MPa})$} & \multicolumn{2}{|c|}{$\lambda_{\text {rup }}$} & \multicolumn{2}{|c|}{$\mathrm{E}_{\text {physio }}(\mathrm{MPa})$} \\
\hline & $\leq 55$ & $>55$ & $\leq 55$ & $>55$ & $\leq 55$ & $>55$ \\
\hline Mean $\pm \mathrm{TE}$ & $2.18 \pm 0.52$ & $0.94 \pm 0.07$ & $1.5 \pm 0.04$ & $1.33 \pm 0.03$ & $1.19 \pm 0.18$ & $2.72 \pm 0.3$ \\
\hline $\mathbf{N}$ & 8 & 23 & 8 & 23 & 8 & 23 \\
\hline
\end{tabular}

Table A2. Statistical distributions (mean and typical error) for each testing type (bulge inflation, uniaxial tension along the circumferential and axial direction) for $\sigma_{\text {rup }}$ and $\lambda_{\text {rup. }}$.

\begin{tabular}{|c|c|c|c|c|}
\hline \multirow{2}{*}{$\begin{array}{c}\text { Patients }>55 \\
\text { years old }\end{array}$} & \multicolumn{2}{|c|}{ Uniaxial test (circumferential) } & \multicolumn{2}{|c|}{ Uniaxial test (axial) } \\
\hline & $\sigma_{\text {rup }}(\mathrm{MPa})$ & $\lambda_{\text {rup }}$ & $\sigma_{\text {rup }}(\mathrm{MPa})$ & $\lambda_{\text {rup }}$ \\
\hline Mean $\pm \mathrm{TE}$ & $1.4 \pm 0.16$ & $1.65 \pm 0.06$ & $0.66 \pm 0.09$ & $1.58 \pm 0.07$ \\
\hline $\mathbf{N}$ & 9 & 9 & 7 & 7 \\
\hline
\end{tabular}


Table A3. Statistical distributions (mean and typical error) for both populations ( $E_{\text {physio }}<1$ and $E_{\text {physio }} \geq 1$ ) for $\sigma_{\text {rup, }}, \lambda_{\text {rup }} \gamma_{\text {stress }}, \gamma_{\text {stretch }}$ and $E_{\text {physio. }}$.

\begin{tabular}{|c|c|c|c|c|c|c|c|c|c|c|}
\hline \multirow{2}{*}{ Bulge test } & \multicolumn{2}{|c|}{$\sigma_{\text {rup }}(\mathrm{MPa})$} & \multicolumn{2}{|c|}{$\lambda_{\text {rup }}$} & \multicolumn{2}{|c|}{$\gamma_{\text {stress }}$} & \multicolumn{2}{|c|}{$\gamma_{\text {stretch }}$} & \multicolumn{2}{|c|}{$\mathrm{E}_{\text {physio }}(\mathrm{MPa})$} \\
\hline & $\mathrm{E}_{\text {physio }}<1$ & $E_{\text {physio }} \geq 1$ & $\mathrm{E}_{\text {physio }}<1$ & $E_{\text {physio }} \geq 1$ & $E_{\text {physio }}<1$ & $E_{\text {physio }} \geq 1$ & $E_{\text {physio }}<1$ & $E_{\text {physio }} \geq 1$ & $\mathrm{E}_{\text {physio }}<1$ & $E_{\text {physio }} \geq 1$ \\
\hline Mean $\pm \mathrm{TE}$ & $0.77 \pm 0.1$ & $1.09 \pm 0.09$ & $1.49 \pm 0.03$ & $1.33 \pm 0.03$ & $0.19 \pm 0.03$ & $0.15 \pm 0.01$ & $0.87 \pm 0.01$ & $0.93 \pm 0.01$ & $0.74 \pm 0.06$ & $2.84 \pm 0.33$ \\
\hline $\mathbf{N}$ & 5 & 22 & 5 & 22 & 5 & 22 & 5 & 22 & & 22 \\
\hline
\end{tabular}


Despite their medical importance, rupture properties of ascending thoracic aortic aneurysms (ATAA) subjected to biaxial tension were inexistent in the literature. In order to address this lack, our group developed a novel methodology based on bulge inflation and full-field optical measurements. Here we report rupture properties obtained with this methodology on 31 patients. It is shown for the first time that rupture occurs when the stretch applied to ATAAs reaches the maximum extensibility of the tissue and that this maximum extensibility correlates strongly with the elastic properties. The outcome is a better detection of at-risk individuals for elective surgical repair. 


\section{ACCEPTED MANUSCRIPT}
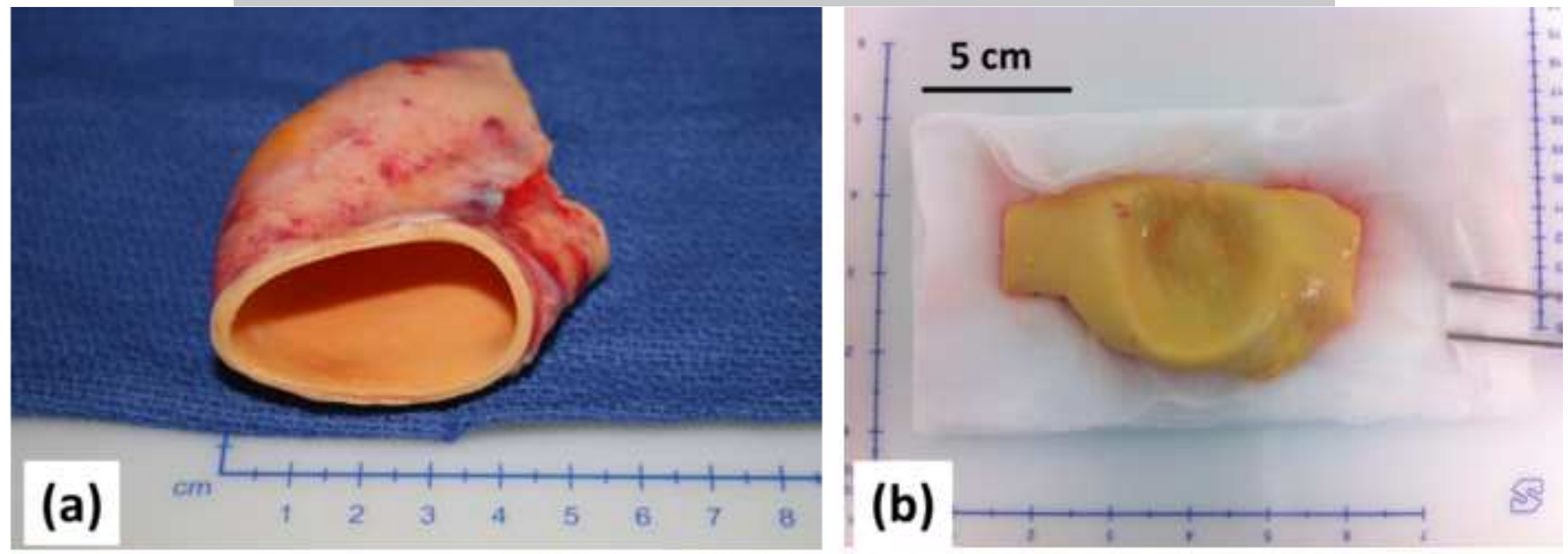

$5 \mathrm{~cm}$
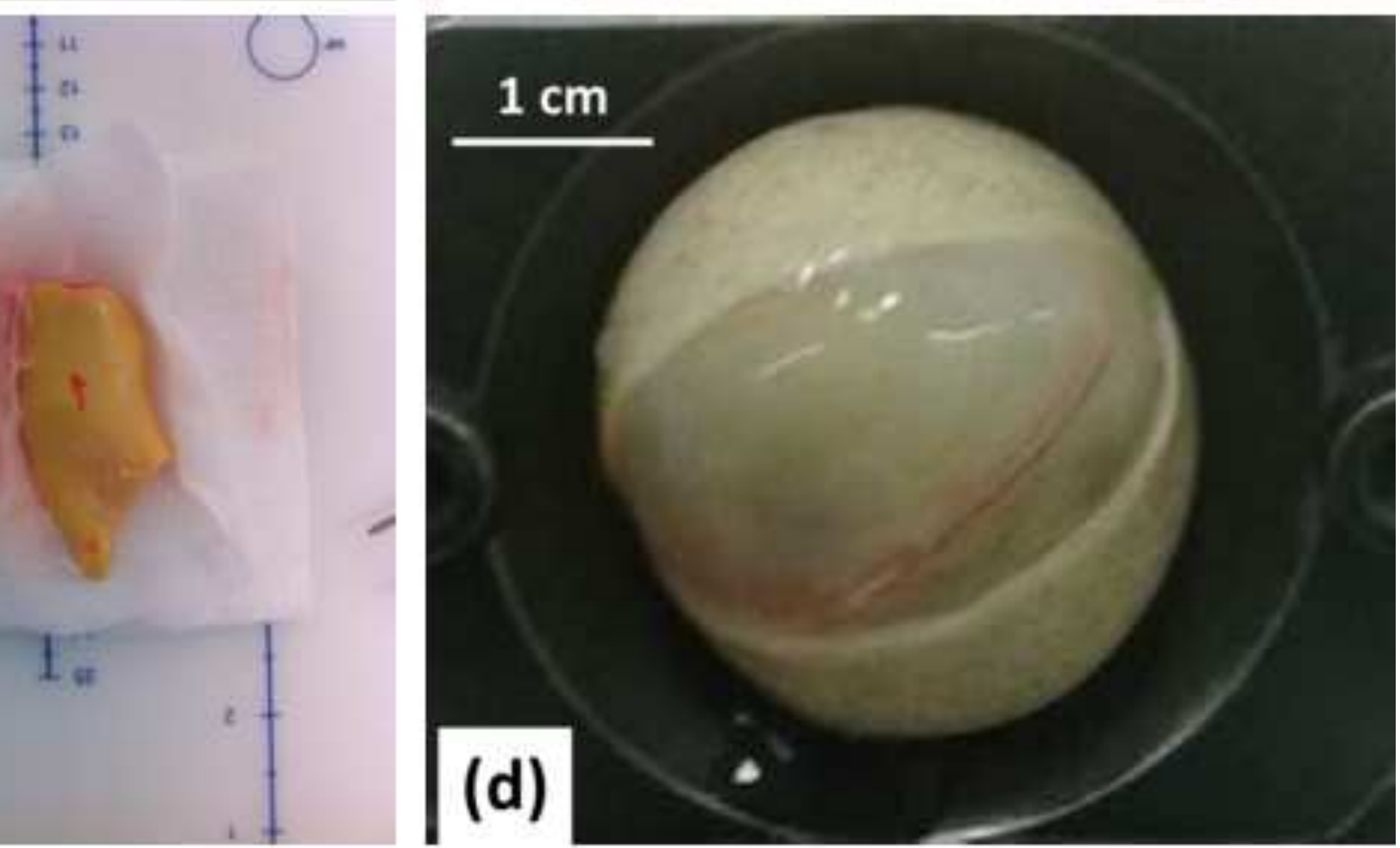

(c)

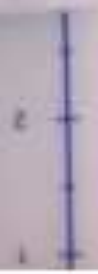

(d) 
(a)

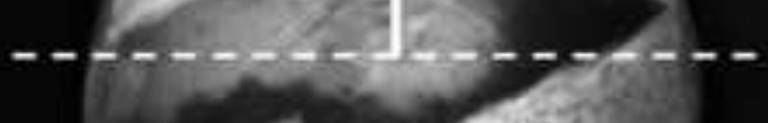

$\mathbf{e}_{2}$

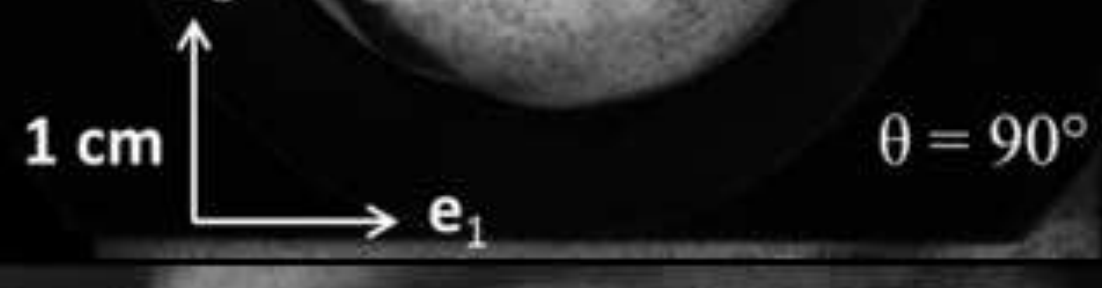

(c)

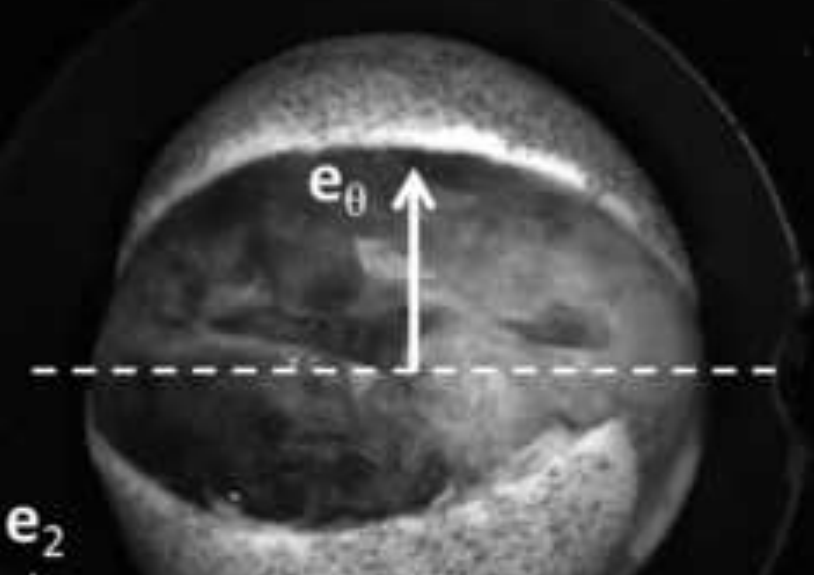

$1 \mathrm{~cm} \longleftrightarrow \mathrm{e}_{1}$

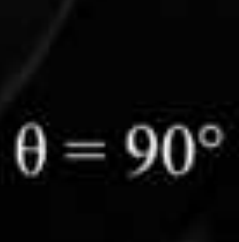

(b)

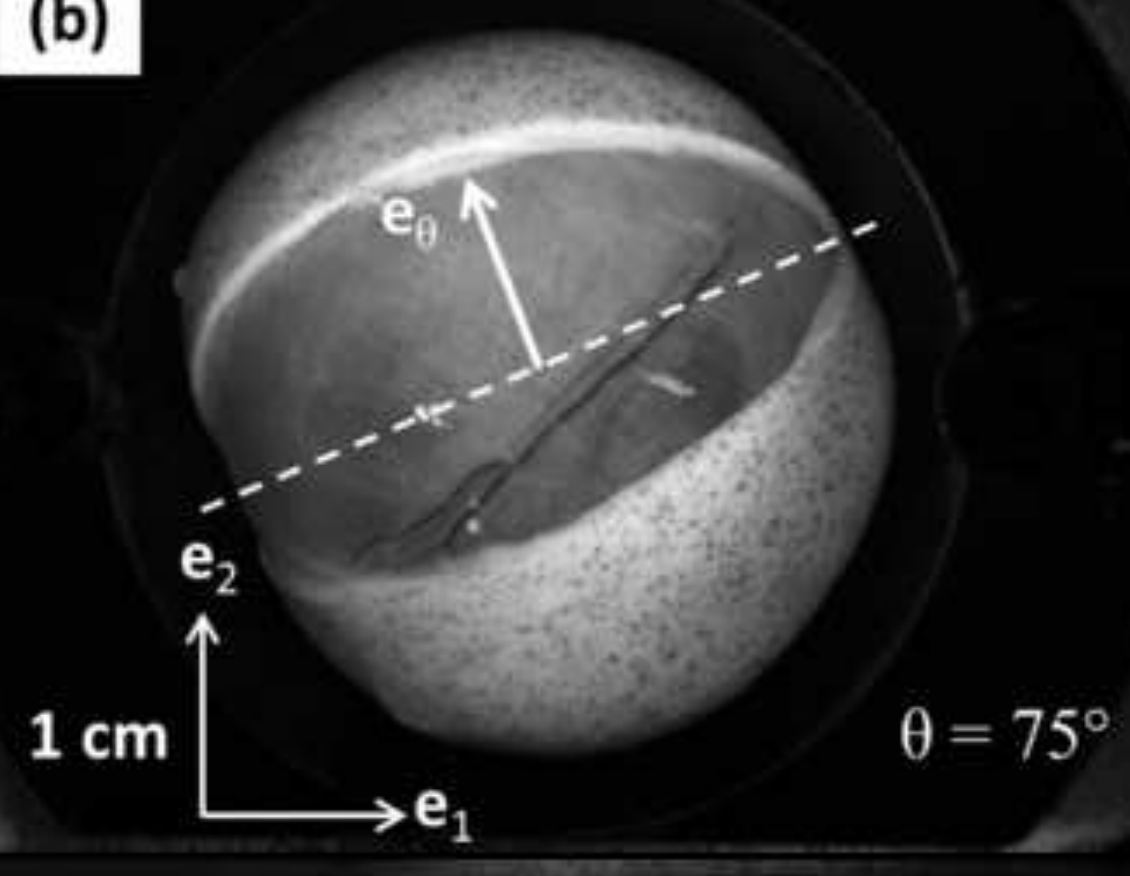

(d)
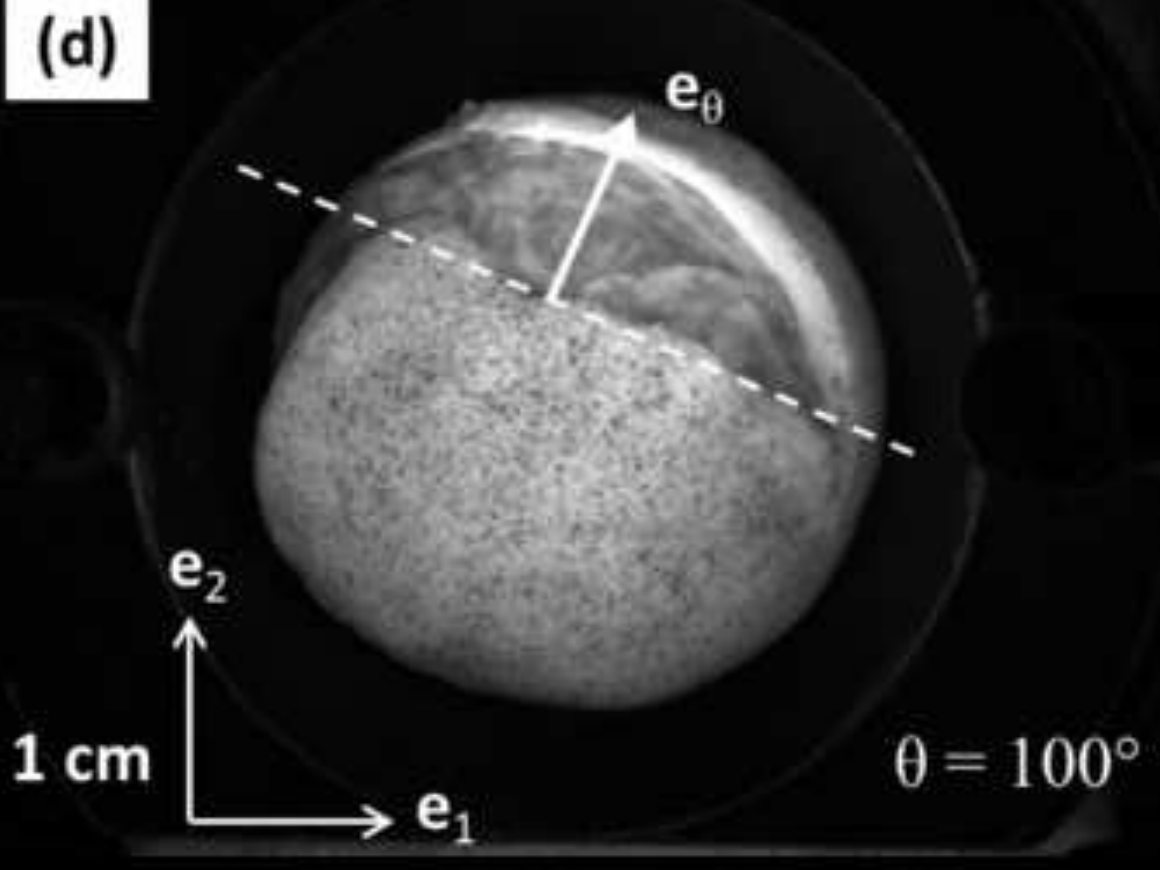


\section{ACCEPTED MANUSCRIPT}

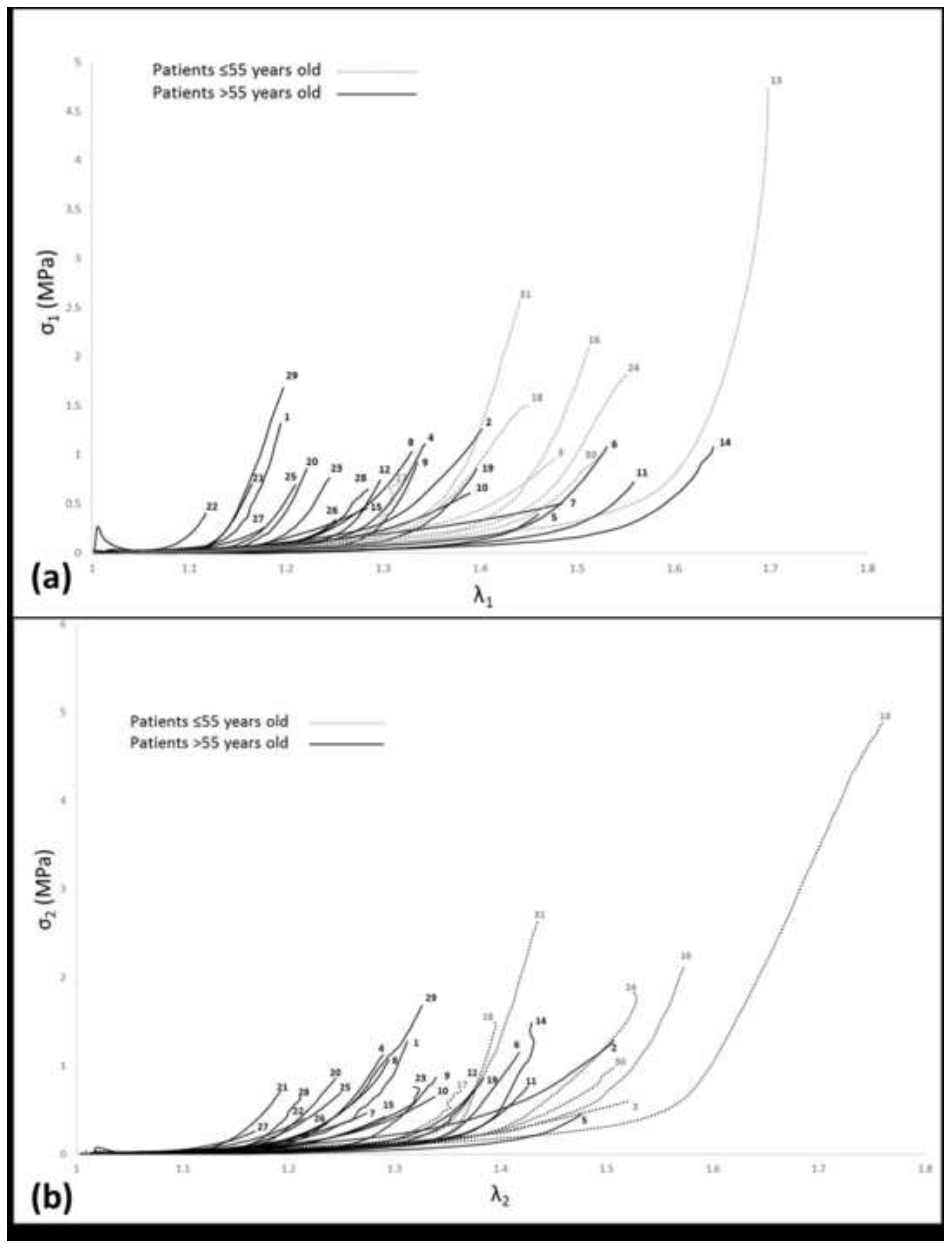

(b)

Patients $\leq 55$ years old

Patients $>55$ years oid

Patients 555 years old

Patients $>55$ years old

$=$

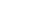




\section{ACCEPTED MANUSCRIPT \\ $\triangle C O E P$}

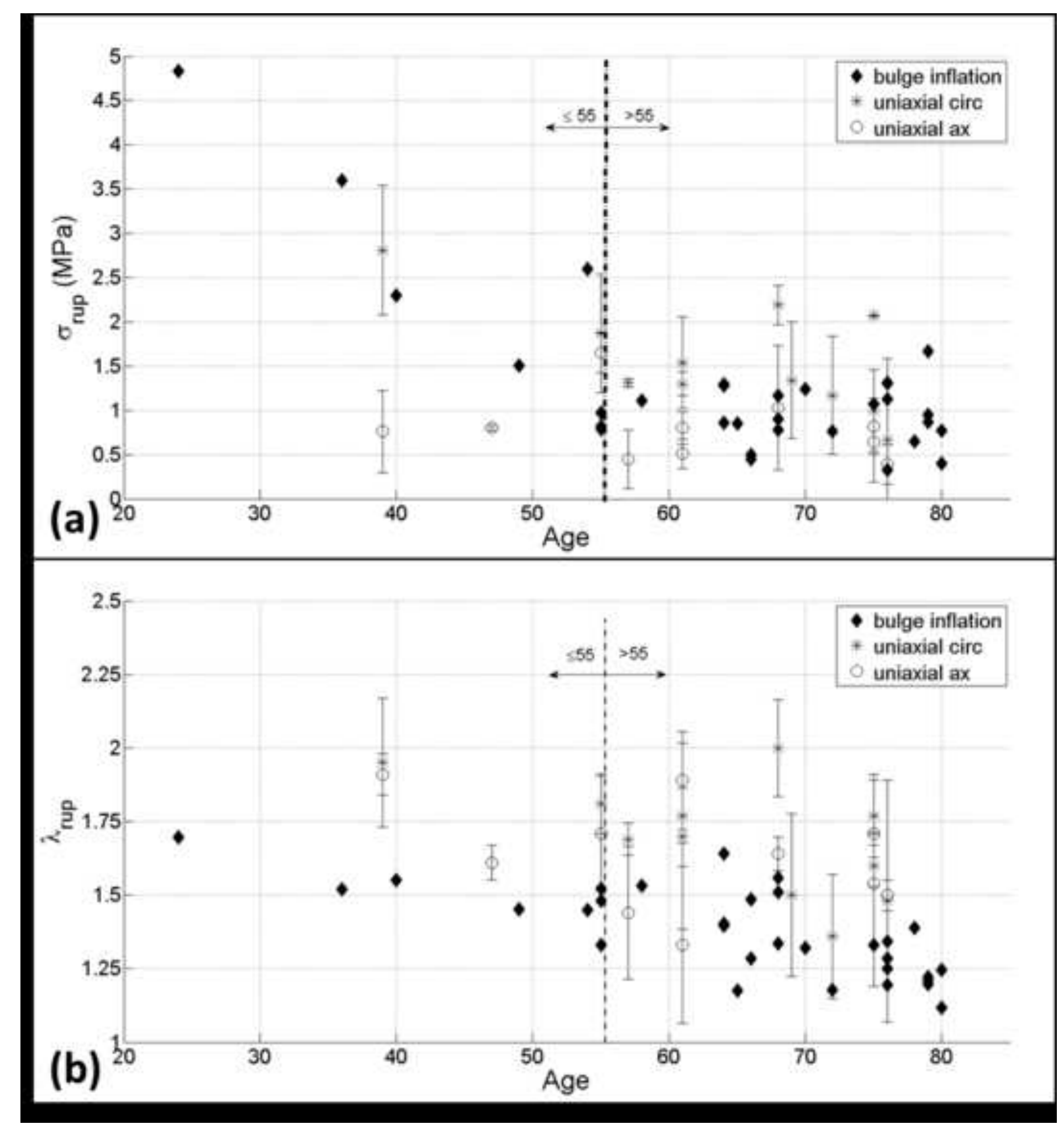

Figure 4

- bulge inflation

+ uniaxial circ

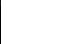

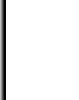
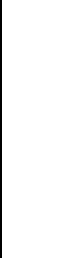
Figure 5

ACCEPTED MANUSCRIPT
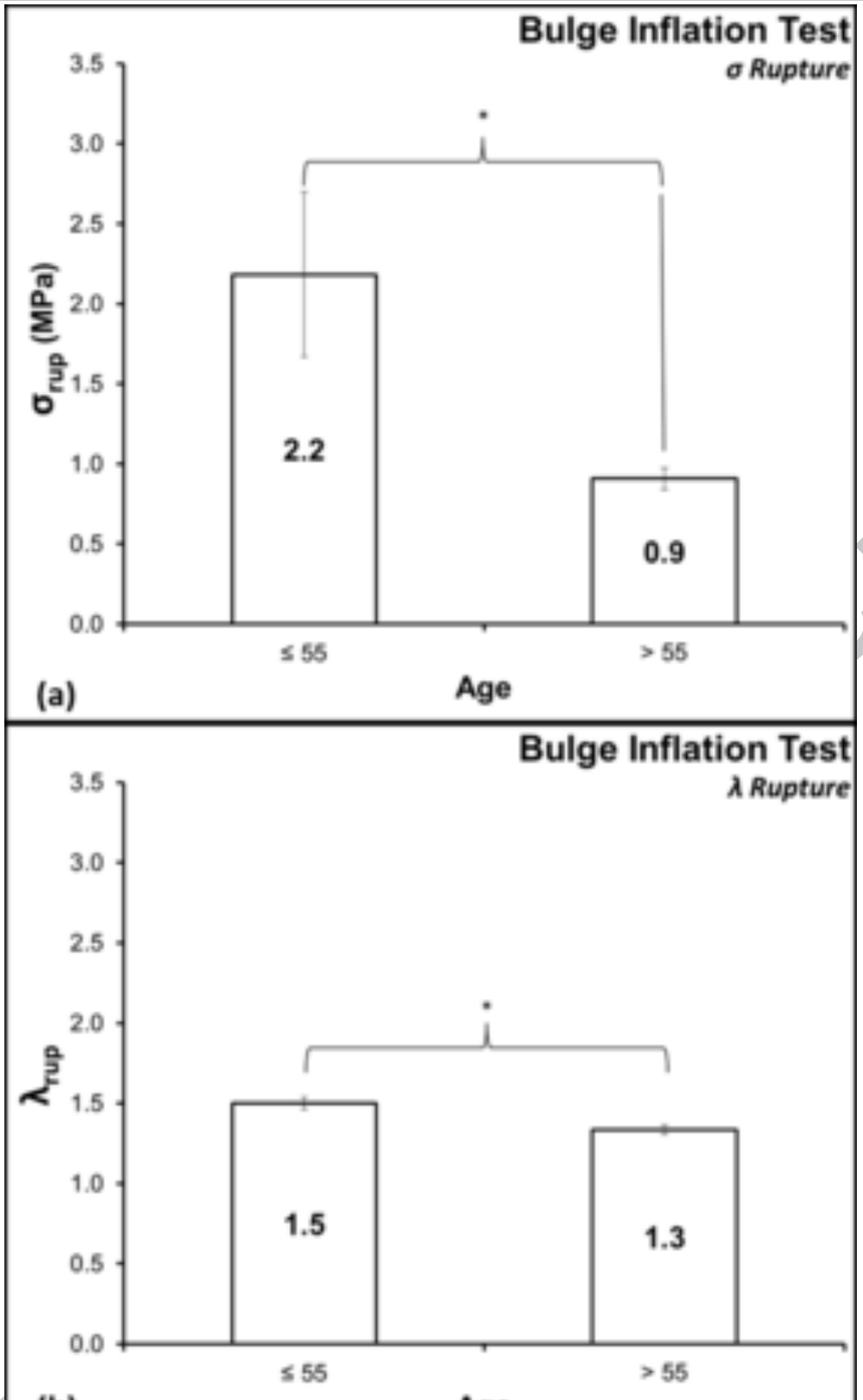

(b)

Age

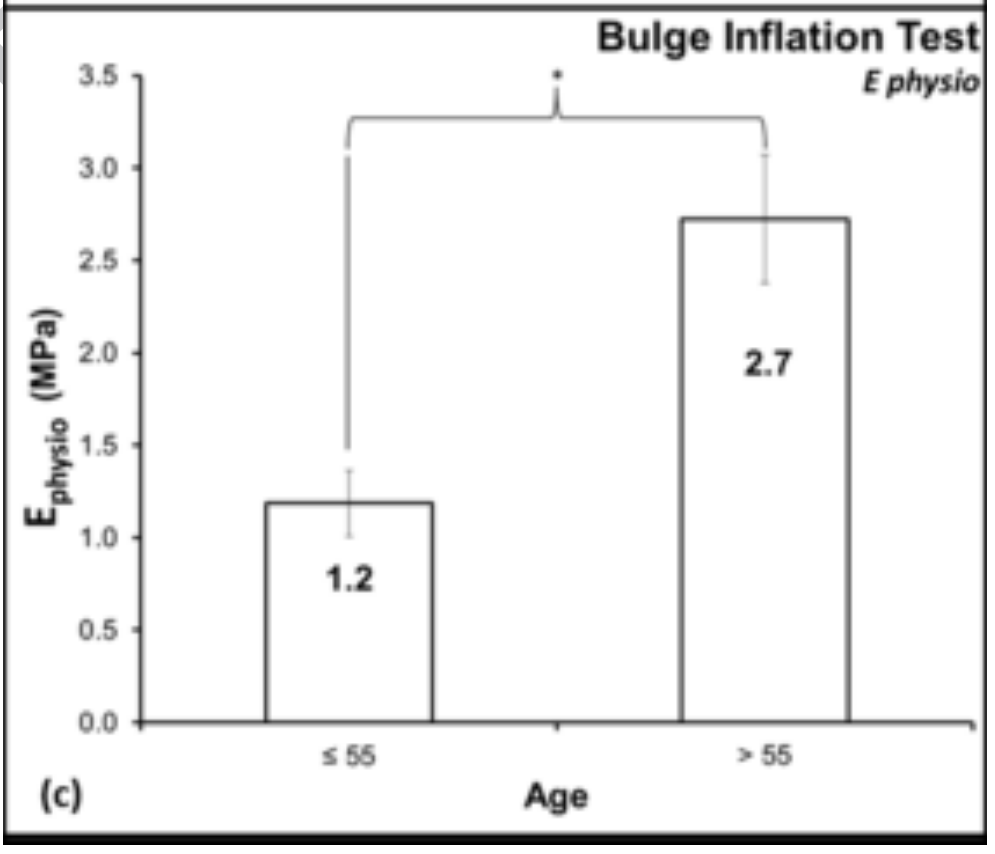




\section{ACCEPTED MANUSCRIPT}
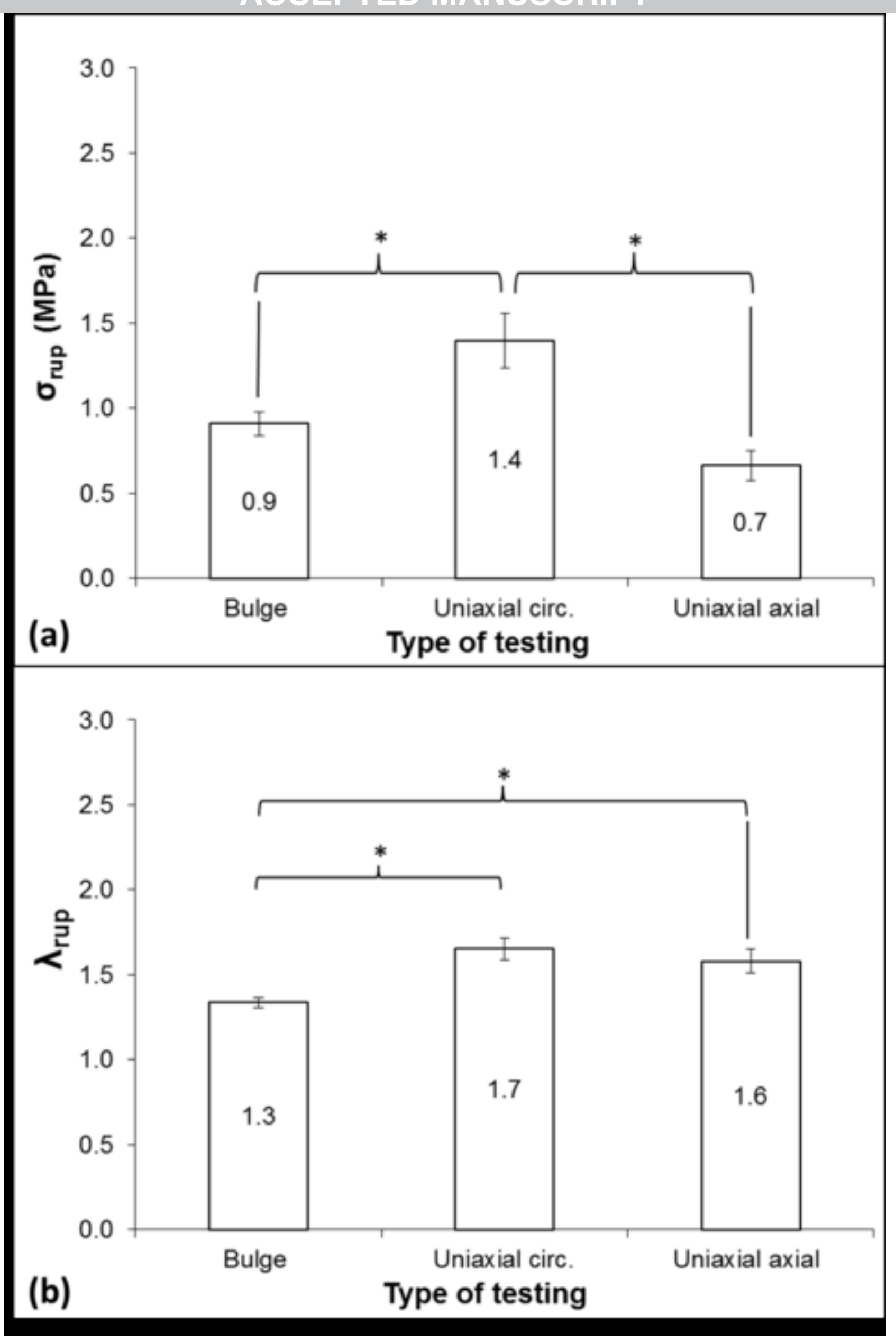


\section{Aneurysm of the ascending aorta}
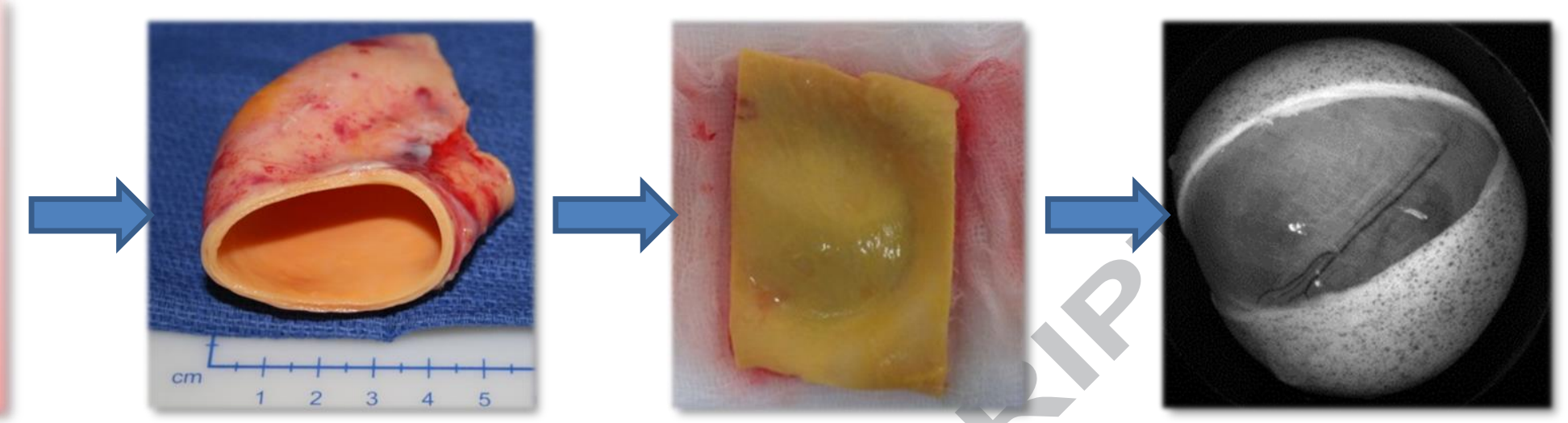

Bulge inflation rupture test

31 human specimens

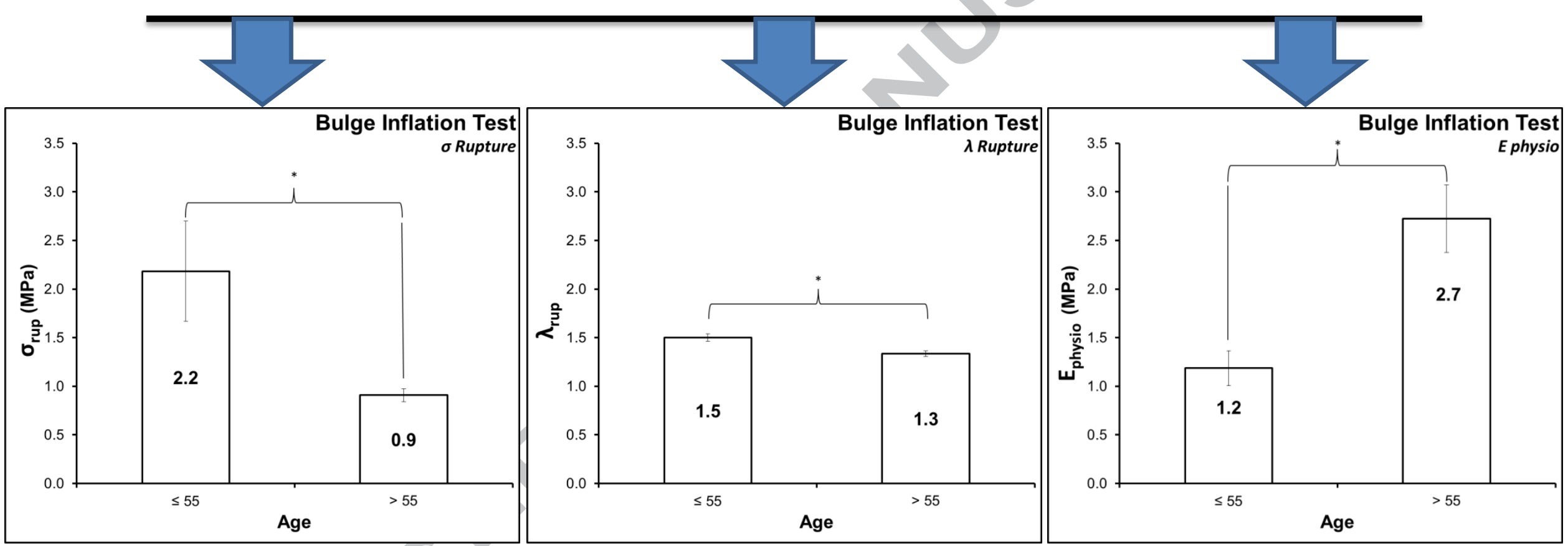

